\title{
Three-dimensional numerical model of heat losses from district heating network pre-insulated pipes buried in the ground
}

\author{
J. Danielewicz ${ }^{1}$, B. Śniechowska ${ }^{1}$, M.A. Sayegh ${ }^{1}$, N. Fidorów ${ }^{1}$, H. Jouhara ${ }^{2}$ \\ ${ }^{1}$ Institute of Air Conditioning and District Heating, Faculty of Environmental Engineering, Wrocław University of Technology, C. K. Norwida St. 4/6, 50- \\ 373 Wrocław, Poland \\ ${ }^{2}$ Institute of Energy Futures, RCUK Centre for Sustainable Energy Use in Food Chains (CSEF), Brunel University, Uxbridge, Middlesex UB8 3PH, UK, \\ E-mail: hussam.jouhara@brunel.ac.uk, Tel: +44 (0) 1895267805; Fax: +44 (0) 1895269777. \\ ${ }^{*}$ Corresponding Author
}

\begin{abstract}
The purpose of the paper is to investigate the challenges in modeling the energy losses of heating networks and to analyse the factors that influence them. The verification of the simulation was conducted on a test stand in-situ and based on the measurements of the testing station, a database for the final version of the numerical model was developed and a series of simulations were performed. Examples of the calculated results are shown in the graphs. The paper presents an innovative method of identify the energy losses of underground heating network pipelines and quantify the temperature distribution around them, in transient working conditions. The presented method makes use of numerical models and measured data of actual objects.

The dimensions of the pipelines used were six meters wide, eight meters high and one meter in depth, while they were simulated under conditions of zero heat flow in the ground, in the perpendicular to the sides direction of the calculated area and considering the effects of ground's thermal conductivity. The mesh was developed using advanced functions, which resulted its high quality with the average orthogonal quality of 0.99 (close to 1.00) and Skewness of 0.05 (between 0.00 and 0.25 ). To achieve better accuracy of the simulation model, the initial conditions were determined based on the numerical results of a three-dimensional analysis of heat losses, in steady state conditions in a single moment. The validation process confirmed the high quality of the model, as the differences between the ground temperatures were approximately $0.1^{\circ} \mathrm{C}$.
\end{abstract}

\begin{tabular}{lll} 
Nomenclature & \\
$C$ & specific heat & $\mathrm{kJ} /(\mathrm{kg} \cdot \mathrm{K})$ \\
$d_{w t}$ & pipe wall thickness & $\mathrm{m}$ \\
$D N$ & nominal diameter & $\mathrm{m}$ \\
$D_{i}$ & outer diameter of insulation & $\mathrm{m}$ \\
$D_{o}$ & outer diameter of pipe casing & $\mathrm{m}$ \\
$D_{\text {inn }}$ & inner diameter of the pipe & $\mathrm{m}$ \\
$D_{\text {out }}$ & outer diameter of the pipe & $\mathrm{m}$ \\
$S$ & distance & $\mathrm{m}$ \\
$T, t$ & Temperature & ${ }^{\circ} \mathrm{C}$ \\
$T_{s}$ & network supply water temperature & ${ }^{\circ} \mathrm{C}$ \\
$T_{r}$ & network return water temperature & ${ }^{\circ} \mathrm{C}$ \\
$t_{o}$ & outside air temperature & ${ }^{\circ} \mathrm{C}$ \\
$t_{a}$ & ambient pipeline temperature & ${ }^{\circ} \mathrm{C}$ \\
$T_{g s}$ & ground surface temperature & ${ }^{\circ} \mathrm{C}$ \\
$t_{g r}$ & ground temperature & ${ }^{\circ} \mathrm{C}$ \\
$w$ & soil moisture & $\%$ \\
$w_{v}$ & volumetric soil moisture & $\mathrm{kg} / \mathrm{m}^{3}$ \\
$\dot{V}_{n}$ & network water volume flow & $\mathrm{m} 3 / \mathrm{s}$ \\
$V_{w}$ & wind velocity at the ground surface & $\mathrm{m} / \mathrm{s}$ \\
\hline
\end{tabular}


Greek symbols

$\begin{array}{lll}\rho & \text { Density } & \mathrm{kg} / \mathrm{m}^{3} \\ \alpha & \text { convective heat transfer coefficient } & W /\left(\mathrm{m}^{2} \cdot \mathrm{K}\right) \\ \lambda & \text { thermal conductivity coefficient } & W /(\mathrm{m} \cdot \mathrm{K})\end{array}$

\section{INTRODUCTION}

\subsection{District heating and district heating networks characteristics}

The heating network of Poland provides centralised district heating to more than 300 cities and 15 million residents $[1,2]$. Figure 1 shows the percentage use of district heating systems for the heating needs supplement in selected countries. According to the figure, the production and distribution of heat in centralised heating systems cover $95 \%, 60 \%$ and $52 \%$ of the needs in Iceland, Denmark and Poland, respectively [1].

In Poland, the vast majority of district heating systems use coal as an energy source, despite the fact that the process of its combustion generates air pollution; however, it should be mentioned that such systems confer the possibility of exhaust gases purification. In addition, gases and dusts emitted to the atmosphere have adverse effects on living organisms. Furthermore, the surface of the suspended particulates can adsorb organic compounds of different chemical classes forming a complex mixture of unknown biological properties [3-9]. Even so, for many years to come coal will be one of the basic energy sources for the production of electricity and heat.

The network transmission and distribution of heat loss is one of the key factors in the optimal design of district heating systems, which includes various pipe configurations, like flexible pre-insulated twin pipes with symmetrical or asymmetrical insulation, double pipes, triple pipes and a 2D-modeling analysis of pipes in computer software with the use of the finite element method (FEM) [10-12].

One of the means to improve the energy efficiency of district heating is to reduce the heat losses at the transmission (distribution), which will lead to a more sustainable and efficient designs of district heating networks [13-17]. For district heating application the following types of construction may be distinguished $[18,19]$ :

- overhead - located above the ground on poles or any other supporting structures,

- aboveground - arranged on the foundations, directly on the ground surface,

- underground - located in the ground and arranged in the tunnels or district heating channels, and placed directly in the ground (such as pre-insulated pipe technologies).

Currently, the most common configuration of placing pipelines is their direct placement in the ground. In contrast, aboveground systems are implemented only in exceptional cases, when underground systems show lack of technical feasibility or their operating cost is considered to be unaffordable.

\subsection{Heat losses in district heating networks}

The main factor influencing the energy losses of heating networks is network leakages, which cause the water to diverge from its channel and to transfer the heat from the interior of pipelines to the environment.

Heat losses occurring as a result of network water losses refer to both network and heat distribution units, as well as internal central heating systems supplied directly from the network. The main cause of network water loss can be "microdamages" in the pipelines; leakages of the heat sources, the heat distribution units or the main pipelines, as well as leakages of working fluid caused by a breakdown removal or planned repairs [20]. 
Based on the presented data of figure 3, the average rate of heat losses lies within the range of $7.6 \%$ to $27.8 \%$. On the basis of references and conducted analysis, it was found that [21]:

- Due to simplified assumptions concerning the input data, the theoretical calculations may not reflect the real heat losses occurring in the operated district heating systems.

- Due to the lack of clear opinion concerning the temperature of the piping surrounding used in the calculations of the heat loss, the problem of reference temperature of the ground should be solved.

- The thermal conductivity of the soil, surrounding the pre-insulated piping, may have a significant impact on the results of the heat loss calculation; for this reason, the calculations should take into account the correct thermal conductivity around the pipe buried in the ground. This is particularly important in the case of modeling the dynamic working conditions of the district heating network.

- The steady state analysis does not reflect the actual working conditions of district heating network; it represents only the state, which occurs under certain conditions.

- The described analytical methods determine the heat losses, do not provide accurate results in the case of the transient heat transfer [21]; to compensate any discrepancies between the theoretical and the actual heat losses, the application of numerical computational methods and the use of actual data should be examined.

- The accuracy of numerical methods varies and depends on the method of calculations and the boundary and initial conditions of the model.

Based on previous studies, it was found that the fulfillment of the main objective of the work described in the paper requires the implementation of the following tasks:

- Design, construction and commission of the research measuring stand in the real district heating system.

- Development of a numerical model, taking into account the measurement data, for analysing the heat transfer in pre-insulated district heating pipelines buried in the ground.

- Identification and justification of the proposed boundary and initial conditions for the numerical model.

- Verification of the numerical model based on experimental studies.

\section{MATERIALS AND METHODS}

\subsection{Test facility design}

Figure 4 shows the schematic diagram of the measuring station, located in the lecture building of Wroclaw University of Technology, which consists of the following elements:

- The measuring and collection system for the ground temperature,

- The measuring and collection system for the outdoor air temperature,

- The measuring and collection system for the volumetric humidity of the soil around the pipeline,

- The measuring system in the heat transfer station (for the district heating water temperature and flow).

The district heating of the building includes two pre-insulated pipes with nominal diameter of DN 40, which consists of a steel carrier pipe, thermal insulated with rigid polyurethane foam (PUR) and an outer pipe jacket of high density polyethylene (PE-HD). The dimensions of each component of the pipes are given in Table 1. The distance between the pipes' outer coats equals to $19 \mathrm{~cm}$.

The temperature measurement in the ground takes into account only the ground area that surrounds the pipelines. The sensors have been installed in the soil, which can be characterized as a uniform environment along the whole district heating network. The temperature measurement around the pipes was carried out by the temperature sensors IT-CF1 with the transduction element (thermo resistor) Pt100, connected to four channels of the Smart Reader Plus 10 recorder. Three Pt100 sensors were used for measuring the temperature in the ground, while the fourth sensor was used to 
measure the outdoor air temperature. The outside air temperature sensor was located approximately $15 \mathrm{~cm}$ above the ground surface in the same vertical plane, where in the ground temperature sensors were located. Measurements were taken every 10 minutes, saved in the internal Smart Reader Plus 10 memory logger and later on they were imported to the computer.

For the recording of the volumetric soil moisture around the pre-insulated district heating pipelines, six ECHO 5-TM probes, and two EM-50 data recorders were used, along with the Echo2 Utility PC software of Decagon Devices Inc. for configuring the data. The measurements of the volumetric soil moisture were programmed with an interval of 10 minutes. After reaching the measurement time, the registration system calculated the average of the readings performed every 60 seconds.

The heat transfer station, located in the Kamstrup Multical Building, was implemented with a 601- type heat meter, equipped with a pair of Pt 500 temperature sensors and an Ultra flow 65-S/R flow sensor. The registration system used for the data recording had two carriers, one on the hard disk of the microcomputer and one on the SD memory card. For reading and recording the data, the software "Rejestrator LC" was used.

The heating operation monitoring system has been used for recording and archiving the following data:

- The district heating network supply water temperature $\left(T_{s}\right)$

- The district heating network return water temperature $\left(T_{r}\right)$

- Network water volume flow $\left(\dot{V}_{n}\right)$

Data were collected and recorded continuously with a time step of 10 minutes.

\subsection{The three-dimensional numerical model}

CFD modelling of pre-insulated pipes in the ground is a multistage process requiring a number of operations. Numerical modeling was performed using ANSYS 14.5 [22,23] package, with the FLUENT computational software (solver).

Elaboration of the numerical model in ANSYS/Fluent environment required to complete the following steps [21]:

- Elaboration of computational geometry, including the definition of proper dimensions and boundary conditions.

- Constructing a numerical mesh (discretization of the geometric area) using advanced options (Fixed, Mapped, Sizing) for the mesh construction. The mesh quality has been checked using two parameters Orthogonal Quality and Skewness.

- Preparation and characterisation of all calculation domains by defining the thermal and physical properties of all materials used in the model.

- Introduction of additional user defined algorithms in ANSYS/ developed in C++ programing environment and afterwards connected to the FLUENT solver.

- Elaboration of input database using some of the data obtained from the test stand.

- Selection of boundary and initial conditions: the ground temperature or thermodynamic behavior on the edges and fluid temperature and velocity in the pipelines.

- Implementation of numerical calculations with an appropriate time step and correct number of iterations.

- Elaboration of computational simulation results.

- Verification of the results obtained from the numerical model. 


\section{RESULTS AND DISCUSSION}

Network transmission and distribution heat loss estimation is a key factor in the design optemisation process of district heating systems. The reported work addresses this by the development of a 3D computer model that will precisely predict such losses from the district heating network's pre-insulated pipes. The developed methodology enables the selection of the impact area's temperature of pipelines and takes into account the temperature field variations of the ground that surrounds the pipelines.

The main purpose of this paper is to show the process and the results of developing a three-dimentional model, which simulates the heat losses of a district heating network with pre-insulated pipes burried in the ground. Therefore, the results section is divided into three parts concerning the development of the model, the simulation results and the model validation.

\subsection{Model development}

\subsubsection{Geometry area sizing analysis}

The selection of the appropriate pipes' cross sectional area is one of the main factors that influence the profile of temperature distribution of the ground around the district heating network. The difficulty related to the geometrical dimensions of the pipes' area, is also related to the choice of the proper boundary conditions on the lateral surfaces (edges) of their area. Two stages analysis facilitates procedure of geometry size selection.

The first stage of the analysis refers to the selection of appropriate boundary conditions and matching geometrical dimensions; areas of different widths are analysed assuming boundary condition of first kind. The rate of network supply and return water temperatures was set as follow: $T_{s} / T_{r}=130 / 70^{\circ} \mathrm{C}$. The temperature distribution around the pre-insulated district heating pipes have been calculated for an exemplary diameter of DN 40 and constant values of soil temperature at the lateral edges $\left(t_{g r}=10^{\circ} \mathrm{C}\right)$.

Figure 5 presents the graphical results of numerical calculations for exemplary geometric area of four meters high and two meters wide. Based on the results, it can be concluded that the fixed temperature at the side edges of the area interferes with the temperature distribution in the ground. However, these surfaces do not show such temperature distribution in real conditions, due to the fact that the ground temperature changes with the increase of depth, and stabilises after a certain point $[24,25]$. Moreover, constant temperature at the side edges of the area with too narrow geometrical area contributes to fluctuations of the temperature distribution in the soil.

With the proposed approach, proper temperature distribution profiles are obtained as long as one of the initial boundary conditions of the numerical model considers the temperature distribution of the ground and the width of the pipes is big enough. However, the implementation of large geometry dimensions (100 or $200 \mathrm{~m}$ ) may cause difficulties in the discretization stage of the geometrical area and in the generation of high quality mesh, resulting increase of the simulation time. This problem can be solved by changing the boundary condition from first to second kind. One of the assumptions of the new approach is zero heat flow in the ground in the direction perpendicular to the sides of the calculation area. Thus, the significant reduction of the distance of lateral surfaces of the geometrical area from the pipelines is possible.

Based on the simulations, the geometry dimensions of the computational model have been estimated using the second approach to the boundary conditions. Initially, three different values were adopted for the geometrical width (2, 5 and $10 \mathrm{~m}$ ) for the given boundary condition of the second kind on the lateral edges of the geometrical area. Depth of eight meters of the ground has been assumed in all cases. This approach allowed the assumption of constant temperature for the bottom edge of computing area $\left(\mathrm{t}_{\mathrm{gr}}=8^{\circ} \mathrm{C}\right) \quad[19,26,27]$. The input data was assumed as exemplary values of the external temperature $\left(t_{o}=-15.7^{\circ} \mathrm{C}\right)$ and network temperatures $\left(\mathrm{T}_{\mathrm{s}} / \mathrm{T}_{\mathrm{r}}=125.2 / 66.4^{\circ} \mathrm{C}\right)$, which have been registered on the test stand during heating season. Figure 6 presents the results of the temperature distribution analysis of the ground around the district heating networks. 
On figures 8,9 and 10, it can be seen that in the models of 5 and 10 meters the isothermal lines have similar distribution. Models with two meters width may be too narrow. The calculation results presented in Figure 6 are only the graphical representation of the performed simulations. For this reason, the charts are additionally supplemented with vertical temperature profiles situated in different distances in relation to the district heating network (the distribution of profiles is presented on the diagram in Figure 7).

The discrepancies in the results of the temperature distribution are particularly evident in the geometric model with the two meters width rather than the models of five and ten meters wide. Between the models of five and ten meters wide, the differences are considerably small. The mean percentage error for models of five and ten meters wide is approximately $1.5 \%$, while for models of two and ten meters wide is about $21 \%$. In order to reduce the impact of errors on the results, and maintain small geometric dimensions, the specifications of the five meters model have been increased by 1 meter.

The obtained temperature profiles were compared and the results of this comparison are shown in Figures 8 and 10. The temperature distribution of the six meters wide model perfectly coincides with the distribution of the ten meters model. On this basis, ultimately it has been assumed that the width of the area will be equal to 6 meters.

Based on the previous analysis, the numerical calculations will be carried out in the model of six meters width, eight meters high and one meter depth.

\subsubsection{Discretization}

The development of computational mesh is a crucial task before define the boundary conditions and start the calculation process. The stage of discretization is of great importance and the success of the whole computational procedure depends on it. In ANSYS 14.5 PC application, it is possible to generate the mesh automatically or developing it independently based on available advanced auxiliary options offered by the program.

Due to the low quality of the mesh generated by the program, it has been decided to use the advanced options for the mesh construction.

Numerical mesh can be created from various kinds of computational cells. Most frequently used are the following types $[28,29]:$

- $\quad$ "Tetra" - tetrahedral, in the form of pyramid with a triangle base.

- "Hexa" - hexahedral, in the form of a prism with quadrilateral base.

- "Pyramid"/"Penta" - in the form of pyramid with quadrilateral base.

- "Prism"/"Wedge" - in the form of a prism with triangle base (so called Prism).

In discretization the most often chosen element is the simplest one with four nodes ("Tetra"), however it is not recommended [29]. "Tetra" elements are not adaptable, and using them for discrete models can increase the level of errors [29]. The best results can be obtained by subdividing the space into six-sided blocks, with hexahedral cells ("Hexa"). Each mesh needs a quality check, because it can affect the accuracy and stability of the subsequent numerical calculations. The mesh can be considered as correct when the calculated results do not depend on it. The calculation mesh has been selected based on performed convergence test. Six different numerical meshes with various size and number of computational cells were analysed. Finally, the mesh with the minimum effect on the calculated results was selected, which consists of 2,847,777 nodes and 2,770,800 computational "Hexa" type cells, as shown in Figure 11.

Fixed option, allows the user to define his own values of the mesh parameters and this method was firstly used. Therefore, the following parameters of the mesh have been assumed:

- Max face sizing (the preferred size of a single computational cell in the mesh) is equal to $0.05 \mathrm{~m}$.

- Max size (the maximum size of a single computational cell in the mesh) is equal to $0.1 \mathrm{~m}$. 
In default program settings the Pave function, which enables the transition to optional shapes and sizes of single computational cells, is turned on. Therefore, in areas relevant to heat transfer, the Mapped function was applied, since it arranges the regular layers around the pipe based on the forces applied. Without this option, the program would not be capable of generating condense mesh in the steel carrier pipe and in the outer jacket of the pre-insulated pipe. The Mapped function has been assigned to all cylindrical walls and caused the pipe walls division into at least three regular layers (Figure 12).

Using Sizing function, the mesh was condensed in the domains related to the pre-insulated pipes and fine in the surrounding areas. In the computational domain of ground, the mesh is finer but without exceeding the maximum defined computational cell size (Figure 13). The mesh developed in such way is distinctive only in the planes of $x$-axis and $y$-axis. To draw the mesh from these planes along the z-axis plane, the Sweep function has been applied. In the numerical calculations, the three-dimensional model has been used since the boundary conditions can be defined is such way that the network water temperature data calculates the actual velocity.

Therefore, in the final stage of mesh construction, boundary layers were added in the places of fluid solid body interface.

The advanced methods of the mesh generation enable the quality verification process. The parameters of the discretization assessment are the Orthogonal Quality and the Skewness. The Orthogonal Quality indicates the mesh quality and its values are between 0.3 and 1, with the upper limit indicating higher mesh quality [27]. The Skewness refers to the deviations of the cells' shape from the perfect one and indicates high mesh quality when its value is between 0 and 0.25 . If the parameter falls between 0.25 and 0.5 the quality is still good, while Skewness value above 0.75 indicates low level of mesh quality [22]. The Skewness indicator should never exceed 0.9 .

Table 2 summaries the formerly described parameters used for quality assessment. The mesh that used for further calculations is of high quality.

\subsubsection{Computational Domains}

The computational domains of the model are defined as follow (Figure 14):

- Carrier pipe (1),

- Insulation (2),

- Outer jacket (3),

- Sand backfill (4),

- Ground (5),

- Water (6).

In the numerical model the defined computational domains are the thermal conductivity coefficient, the specific heat and the density of the solid or fluid. Based on the literature [27,30-34], the complete data have been obtained and summarised in Table 3.

\subsubsection{Computation algorithm "Variable Lambda"}

The FLUENT program environment enables the creation of user functions called UDFs (User-Defined-Functions). This allows the user to make use of its own algorithms, developed for a specific application. UDF is an independent function defined by the user, which is not built into the computer program or programming environment. This function has been created in $\mathrm{C}++$ programing environment and afterwards connected to the FLUENT solver. It was used in the calculations in order to introduce the time-variation thermal conductivity of the soil around the pre-insulated pipes. Figure 15 shows the changes of the soil volumetric humidity around the pre-insulated pipes during the measurements between 07 April 2012 and 02 May 2012. The profile of the soil volumetric moisture changes of the ground consists of the average values from the six measurement probes localised in the test stand, as shown in Figure 16. 
The average values of the ground volumetric moisture around the pre-insulated pipes were in the range of $14.9-17.8 \%$. Based on measurements, the approximation function describing the dependence of the ground thermal conductivity and ground volumetric moisture was in the range of $10 \%$ to $20 \%$ (Figure 17 ).

Based on the measurements of ground volumetric moisture and the approximation function, the average values of ground thermal conductivity around the pipes were calculated (Figure 18). These values were introduced using the "Variable Lambda" software, written in C++ programing language, and assigned to the "sand backfill" computational domain.

\subsubsection{Development of input database}

The heat losses in district heating network connections were determined based on the assumptions made, regarding the boundary conditions of the model (Section 3.1.6) and the parameters measured in the test stand, based on which the input database was built. The database contains the following parameters:

- Time.

- Outside air temperature.

- Supply water temperature.

- Return water temperature.

- Circulating water velocity calculated on the basis of the measured volumetric flow of network water.

- Volumetric moisture of the soil around the pipeline.

The calculations were performed for the selected time period (19/04/2012 - 02/05/2012) with a single time step of $\Delta t=$ 3600 second. On this basis, 1480 time steps were obtained and 20 iterations were carried out for each one of them.

Figuer 19 represents the measured network water temperature and the outside air temperature on the test stand within the time period assumed for the analysis. Figure 20 shows the circulating water velocity in district heating network connection, which has been calculated based on measurements registered by measuring system.

\subsubsection{Boundary and initial conditions in the numerical model}

Proper development of boundary and initial conditions is essential for the proper operation of the numerical model. Figure 21 represents the scheme, based on which the various types of boundary conditions of the computational model were characterised.

According to the literature research $[27,28]$, and on the outcomes of the simulation calculations at eight meters depth, the ground temperature is constant during the whole year in Poland and is equal to $8^{\circ} \mathrm{C}$. Therefore, the first boundary condition refers to the bottom plane of the model $(4-3-7-8)$ and indicates that the temperature is constant on this surface $\left(t_{4-3-7-8}=8^{\circ} \mathrm{C}\right)$. There is no reason for substantial incensement of the depth of ground in the model, because below 20 meters the ground temperature increases with the depth due to the thermal impact of earth's core [35].

Another boundary condition is set on the sides, front and rear planes of the calculation area (1 - 2 - 3 - 4), (5 - 6 - 7 - 8$),(1$ - 3 - 7 - 5), (2 - 4 - 8 - 6), respectively. In CFD models based on numerical fluid mechanics, this type of condition is called symmetry surfaces. These surfaces are characterised by zero momentum, mass and energy transfer towards orthogonal direction.

On the upper surface of the ground (1-2-5-6), a heat transfer between the outdoor air and the ground occurs. Because of that, a third boundary condition is implemented, which cause the dependency of the provision of the heat transfer coefficient on the type of heat transfer which is occurring on the surface of the given body, the type of fluid, the velocity and direction of fluid flow in relation to the surface of the body. Literature describes various approaches of the heat transfer coefficient adoption in this case. Convection heat transfer coefficient can be calculated using so-called Jürgers calculation formulas, depending on the wind velocity at the surface of the ground $v_{w}$ [34]. 
$\alpha_{e}=7,15 \cdot v_{w}^{0,78}, \frac{w}{\left(m^{2} \cdot K\right)} \quad$ for

$v_{\mathrm{w}}>5 \mathrm{~m} / \mathrm{s}$

$\alpha_{e}=5,80+v_{w}^{0,78}, \frac{w}{\left(m^{2} \cdot K\right)}$ for $v_{\mathrm{w}}<5 \mathrm{~m} / \mathrm{s}$

According to the literature research, the values of heat transfer coefficient may be assumed depending on the wind velocity. For a range of wind velocity values $v_{w}=3.6-4.6 \mathrm{~m} / \mathrm{s}$, the heat transfer coefficient can be equal to $\alpha_{e}=13-14$ $\mathrm{W} /\left(\mathrm{m}^{2} . \mathrm{K}\right)$. Kvisgaard and Bøhm in their works assumed constant value of the heat transfer coefficient equal to $\alpha_{e}=14.6$ $\mathrm{W} /\left(\mathrm{m}^{2} \cdot \mathrm{K}\right) \quad[25,30,34,36]$. In the calculation model, a constant value of heat transfer coefficient $\alpha_{e}=14.6 \mathrm{~W} /\left(\mathrm{m}^{2} \cdot \mathrm{K}\right)$ has been assumed $[30,34,37,38]$.

The computational model requires also the introduction of boundary conditions on the inlets (9) and outlets (10) of two carrier pipes. The "inlet" boundary condition requires defining the values of velocity and temperature. The temperature profiles for inlets of network water were introduced based on the constructed input database. A developed velocity profile of installation water on the supply and return pipeline has been assumed.

For the "outlet" boundary condition, constant static pressure and zero gradients of all dependent variables for perpendicular direction to this border has been assumed in accordance to the guidelines for the adaptation of the boundary conditions for CFD codes users [28].

Initial conditions are substantial in time transient analysis and refer to the distribution parameters at the beginning of the process. The initial conditions for three-dimensional numerical model, which are used for heat loss calculations under dynamic operation conditions of district heating network, has been determined based on the results obtained from threedimensional simulation model of the heat loss for steady state conditions in a single moment (time step 1). The results obtained from the calculations of the model represent the steady-state conditions based on which the initial conditions of three-dimensional model were defined. Based on the analysis performed below, it was found that the developed initialization procedure of the numerical model calculations beneficially affect the time needed to achieve the convergence of the model. In order to illustrate the consequences of the adoption of the default initial conditions, an exemplary analysis has been performed. Figure 22 presents the exemplary results of unitary heat loss calculations obtained on the basis of the numerical model by adopting two types of initial conditions - default and user developed procedure of numerical model calculation initialization.

Based on the results presented in Figure 22, it has been shown that there is a necessity for adjusting the initial conditions to the nature and the parameters of the numerical model (e.g. temperature). Well defined initial conditions enable to achieve correct results even in the first steps of the simulation. This reduces the time required for the calculations and on the errors occurring due to the results from the first period of simulation. Leaving the standard (default) initial conditions of the model results with large discrepancies in the first stage of the simulation requires performance of the additional analysis to eliminate the incorrect series of the results. Therefore, it is recommended to determine the initial conditions independently as calculation results of the first time step, before switching to the transient calculations.

\subsection{Numerical calculations and simulation results}

The method selected for heat loss modeling was RANS (Reynolds Averaged Navier-Stokes Equations), based on statistically averaged equations of motion. Turbulence models using Reynold's concept of the averaged Navier-Stokes equations, offer the possibility of finding the approximate numerical solution of turbulent flow and relatively good modeling results [39]. The results of numerical calculations presented in this paper have been obtained on the basis of half empirical SST (Shear Stress Transport) turbulence model for RANS methods. SST turbulence model is a hybrid model which combines the advantages of the $k-\varepsilon$ and $k-\omega$ models. The $k-\omega$ model is used when the calculations refer to the boundary layers near the wall.

The results of the heat loss calculations based on the numerical model are presented in Figure 23 and Figure 24 . These results were compared with the results of the analytical procedure analysis from ISO 13941 (assuming a constant ground 
temperature surrounding the pipelines). The results of the numerical model are more accurate, since the outcome of the modeling depends on the situation of the previous time step, which definitely corresponds to the actual operating conditions of the district heating system. This is particularly evident in the case of the transitional period, where the dynamics of the changes of the temperature and the network water velocity is large (the start and end of building heating).

\subsection{Verification of the numerical model}

The ground temperature changes in time as simulation results have been compared with the temperature values measured during research (Figure 23 and 24). Figure 25 indicates the points where the temperature sensors were installed.

The first sensor have been located approximately $1 \mathrm{~cm}$ under the outer jacket of the supply pipeline, the second one along with the pipeline axis between supply and return pipe, while the third one approximately $1 \mathrm{~cm}$ under the outer jacket of the return pipeline.

In Figures 26 to 28, the average prediction uncertainty ME (Mean Error), which indicates how much the actual values differ from the estimated values, based on the simulation model, have also been shown. The discrepancy between the simulation and measured values is approximately $0.1^{\circ} \mathrm{C}$ (at the maximum error equals to $1.1^{\circ} \mathrm{C}$ ). On this basis, it is safe to conclude that the developed numerical model reflects very accurately the nature and the dynamics of temperature changes in the ground. The consistent trend of temperature profiles confirms the accuracy of the proposed computational method.

\section{CONCLUSION}

An innovative method for heat loss calculation in pre-insulated district heating network pipes buried in the ground based on a numerical model and measured data has been developed.

This method can be used for the simultaneously monitoring of heat losses and as a tool to determine the instantaneous temperature distribution in the ground around the district heating networks.

The geometry characteristics have great influence on the outcomes of temperature distribution calculations. The choice of first kind boundary conditions is not convenient, due to the fact that the temperature distribution calculations around the district heating networks have been conducted based on the applied forces of the geometry resulting discontinuities in the mesh construction. Assuming that the second kind boundary condition are zero, the heat flow in the ground in the perpendicular to the sides direction of the calculation area allows to reduce the width of the pipes from hundreds of meters to six meters. Thus, the appropriate pipe dimensions for the simulation are $6 \mathrm{~m}$ wide, 8 meters high and $1 \mathrm{~m}$ depth.

It has been shown that considering the temperature of the ground as constant provides only rough estimations of the heat losses of the pre-insulated district heating networks and does not reflect the dynamic operation conditions of the district heating system.

The mesh generated automatically by the ANSYS 14.5 PC application had low quality. The development of proper mesh demanded use of advanced functions. Fixed option has been used to ensure the proper cell dimensions, the Mapped function was implemented to arrange the regular layers around the pipe and the Sizing function to make the mesh more condense in the domain of the pre-insulated pipes. After checking the quality of mesh, the average orthogonal quality was equal to 0.99 (close to 1.00) and the Skewness was 0.05 (between 0.00 and 0.25 ), indicating that way that the mesh is of high quality. 
The model was simulated based on UDFs, in order to secure that the change of the thermal conductivity of the ground was taken under consideration. This consideration is of great importance because of the thermal conductivity of the ground surrounding the pipelines varies due to the volumetric moisture content and if it is not taken into account the accuracy of the heat loses calculations is affected.

It has been shown that there is a necessity for adjusting the initial conditions to the nature and the parameters of the numerical model. A numerical model, of which the initial conditions are well defined, is capable to achieve very accurate results even in the first intervals of the simulation. Therefore, prior to the three-dimensional numerical model for simulating heat losses under dynamic operation conditions of district heating network (transient simulation), a steady-state simulation has been carried out, in order to determine the initial conditions for the simulation. The problem of referencing the initial and boundary conditions in the numerical model for heat losses calculation from district heating network pipelines has been analysed and solved. Properly referenced boundary conditions reduce the computational cross sectional area and simplify the generating calculations of numerical mesh. Properly defined initial conditions enhance the quality of the simulation results and enable them to achieve faster convergence.

The results of the numerical model are more accurate than those calculated on the ISO 13941, since the outcome of the modeling depends on the calculations conducted on the previous time step, which corresponds to the actual operating conditions of the district heating system.

The model has been validated by comparing the calculated and measured ground temperatures. The differences were approximately $0.1^{\circ} \mathrm{C}$, while they did not exceed the value of $1.1^{\circ} \mathrm{C}$, which proves the high accuracy of the proposed model.

The methodology takes into account the soil moisture content which can be applied for temperatures prevailing in heating range up to $130^{\circ} \mathrm{C}$. For higher temperatures the model need further validation to be applicable.

\section{REFERENCES}

[1] P. Bogusławski, Selected aspects of the heat transmission and distribution the view of the law, The Energy Regulatory Office Bulletin. 4 (2010).

[2] J. Danielewicz, K. Gołecki, Guide for boiler room designer, Wroclaw University of Technology Press, Wroclaw University of Technology. (2004).

[3] K. Piekarska, Mutagenicity of airborne particulates assessed by Salmonella assay and the SOS chromotest in Wrocław, Poland, Journal of the Air \& Waste Management Association. 60 (8) (2010) 993-1001.

[4] K. Piekarska, J. Karpińska-Smulikowska, Mutagenic Activity of Environmental Air Samples from the Area of Wrocław, Poland, Polish Journal of Environmental Studies. 16 (5) (2007) 745-752.

[5] K. Piekarska, M. Zaciera, A. Czarny, E. Zaczyńska, Mutagenic and cytotoxic properties of extracts of suspended particulate matter collected in Wrocław City area, Environment Protection Engineering. 35 (1) (2009) 37-48.

[6] V. Lawlor, K. Klein, C. Hochenauer, S. Griesser, S. Kuehn, A. Olabi, et al., Experimental and numerical study of various MT-SOFC flow manifold techniques: single MT-SOFC analysis, Journal of Fuel Cell Science and Technology. 10 (1) (2013) 011003. 
[7] S. Tedesco, K.Y. Benyounis, A.G. Olabi, Mechanical pretreatment effects on macroalgae-derived biogas production in co-digestion with sludge in Ireland, Energy. 61 (0) (2013) 27-33.

[8] J.G. Carton, V. Lawlor, A.G. Olabi, C. Hochenauer, G. Zauner, Water droplet accumulation and motion in PEM (Proton Exchange Membrane) fuel cell mini-channels, Energy. 39 (1) (2012) 63-73.

[9] J.G. Carton, A.G. Olabi, Design of experiment study of the parameters that affect performance of three flow plate configurations of a proton exchange membrane fuel cell, Energy. 35 (7) (2010) 2796-2806.

[10] A. Dalla Rosa, H. Li, S. Svendsen, Method for optimal design of pipes for low-energy district heating, with focus on heat losses, Energy. 36 (5) (2011) 2407-2418.

[11] H. Lund, S. Werner, R. Wiltshire, S. Svendsen, J.E. Thorsen, F. Hvelplund, et al., 4th Generation District Heating (4GDH): Integrating smart thermal grids into future sustainable energy systems, Energy. 68 (0) (2014) $1-11$.

[12] M. Pirouti, A. Bagdanavicius, J. Ekanayake, J. Wu, N. Jenkins, Energy consumption and economic analyses of a district heating network, Energy. 57 (0) (2013) 149-159.

[13] A.G. Olabi, 100\% sustainable energy, Energy. 77 (0) (2014) 1-5.

[14] A.G. Olabi, State of the art on renewable and sustainable energy, Energy. 61 (0) (2013) 2-5.

[15] A.G. Olabi, Developments in sustainable energy and environmental protection, Energy. 39 (1) (2012) 2-5.

[16] A.G. Olabi, Developments in sustainable energy and environmental protection, Simulation Modelling Practice and Theory. 19 (4) (2011) 1139-1142.

[17] A.G. Olabi, The 3rd international conference on sustainable energy and environmental protection SEEP 2009 - Guest Editor's Introduction, Energy. 35 (12) (2010) 4508-4509.

[18] W. Kamler, District Heating. Part II-District Heating Networks, The Polish Scientific Publishers, Issue IV, Warsaw. (1974).

[19] W. Szuman, CHP plants and district heating, PWN, Lodz-Warsaw. (2) (1963).

[20] M. Chorzelski, K. Wojdyga, The tightness of heating systems. Causes and effects of the lack of tightness, Modern District Heating. 12 (207) (2009).

[21] B. Śniechowska, Numerical modeling of heat losses in pre-insulated district heating network pipes buried in the ground, Wroclaw. (2014).

[22] Software ANSYS® Academic Research, Release 14.5, Help System, Coupled Field Analysis Guide, ANSYS, Inc.

[23] S. Anisimov, D. Pandelidis, J. Danielewicz, Numerical analysis of selected evaporative exchangers with the Maisotsenko cycle, Energy Conversion and Management. 88 (0) (2014) 426-441.

[24] B. Biernacka, The study of temperature distribution in the soil at the different depths, District Heating, Ventilation. 9 (2012). 


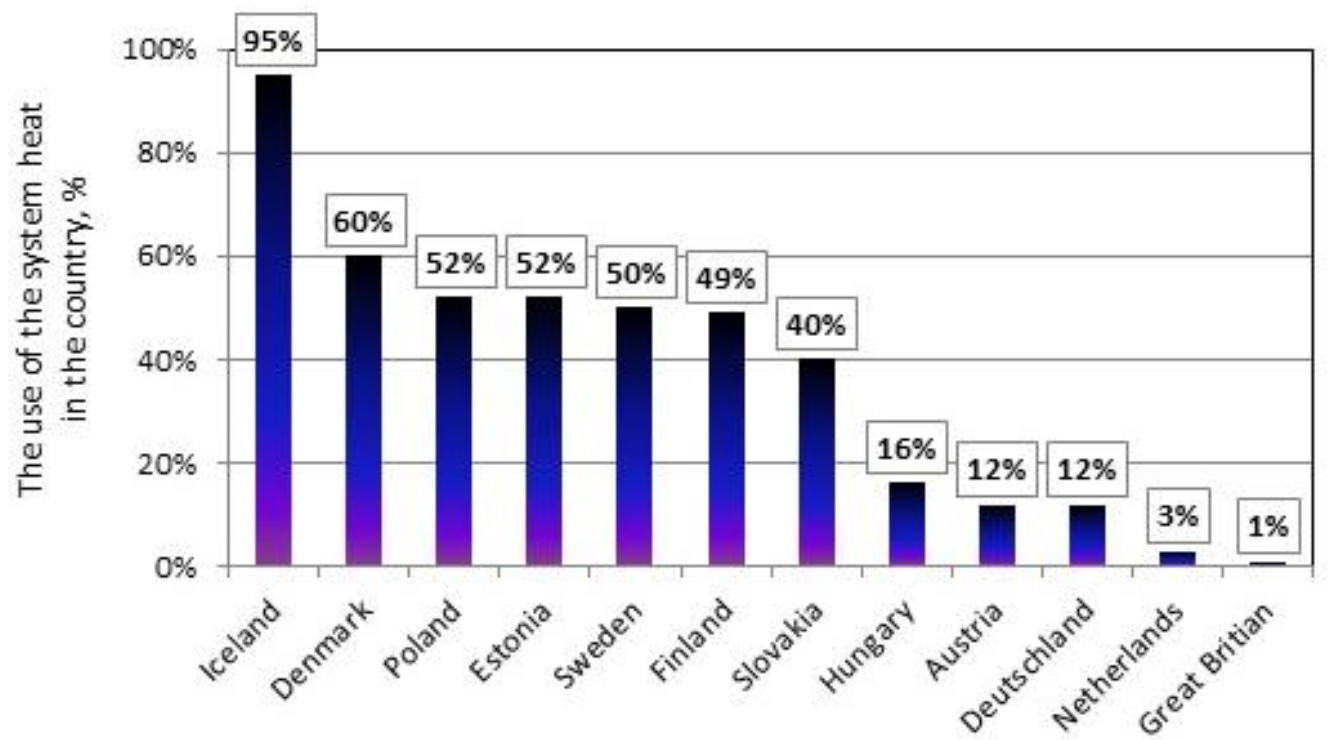

Figure 1: The percentage share of the district heating systems use for the heating needs supplement in selected countries [11]

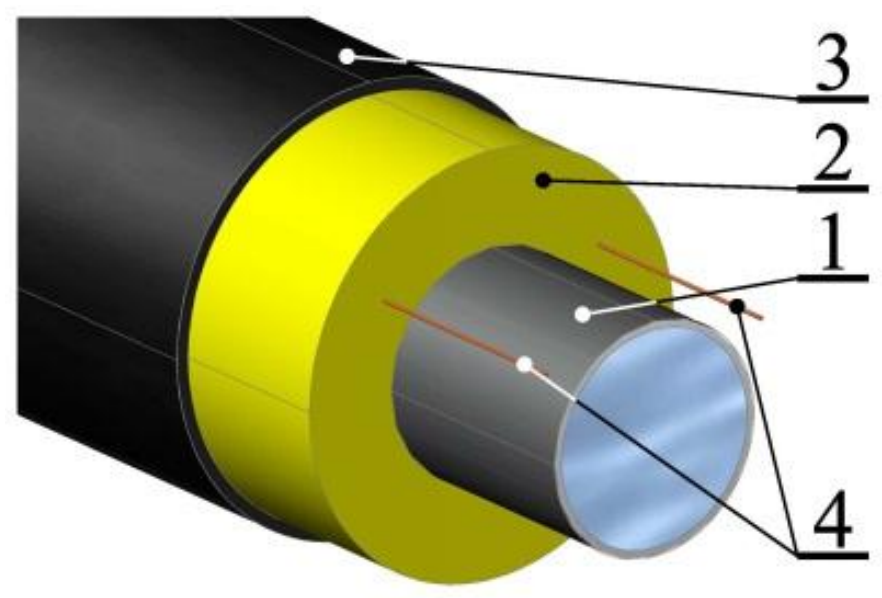

Figure 2: Pre-insulated pipe: 1-steel carrier pipe, 2-PUR insulation, 3- PE-HD outer jacket, 4-wire alarm system [11] 


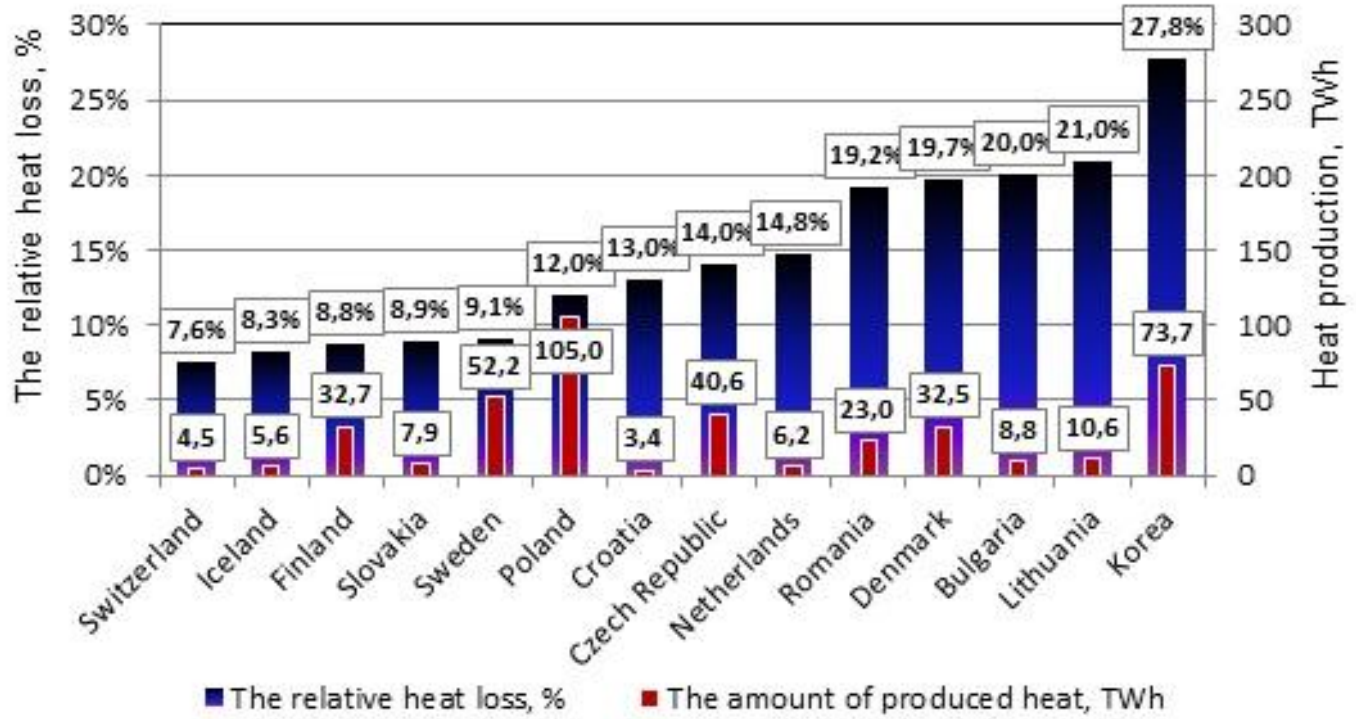

Figure 3: The relative heat loss and the amount of heat produced in district heating systems belonging to selected countries in the world $[12,13]$
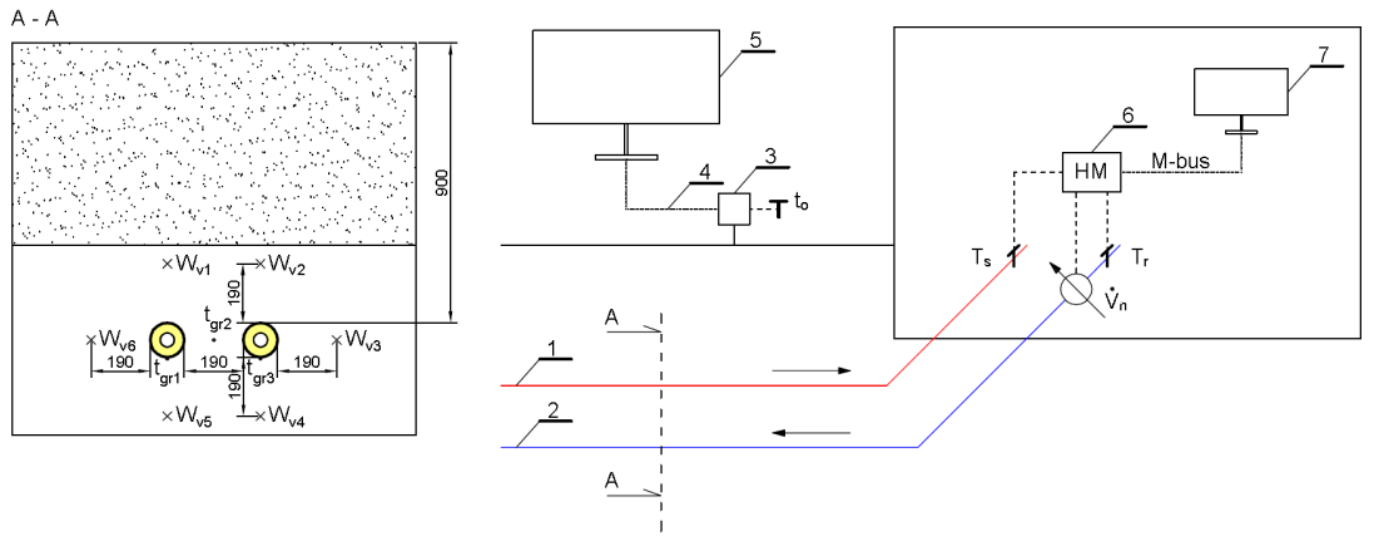

Figure 4: Scheme of the measurement site: 1-flow line (DN 40), 2-return line (DN 40), 3-the temperature record and archive system, 4-the ground volumetric moisture record and archive system, 5-personal computer, 6-Kamstrup Multical 601 heat meter, 7-microcomputer. $t_{0}$-the outside air temperature sensor, $t_{g r}$-the ground temperature sensor, $w_{v}$-the ground volumetric moisture measuring probe [14] 


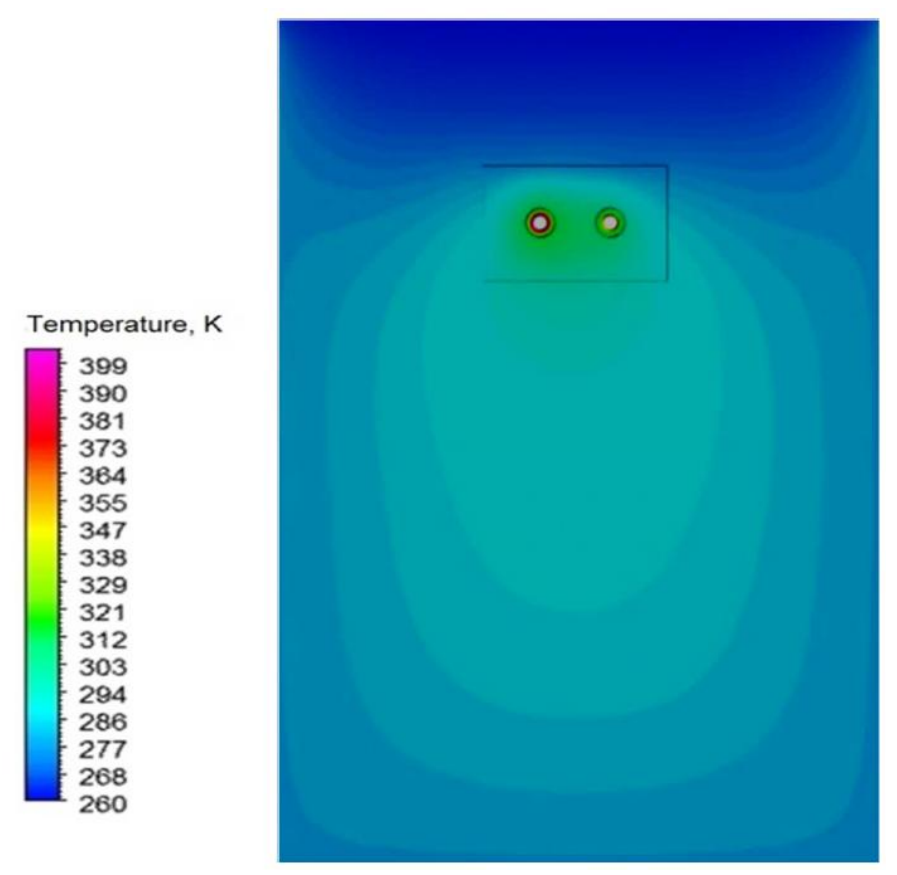

Figure 5: The ground temperature distribution in case of using the wrong types of boundary conditions
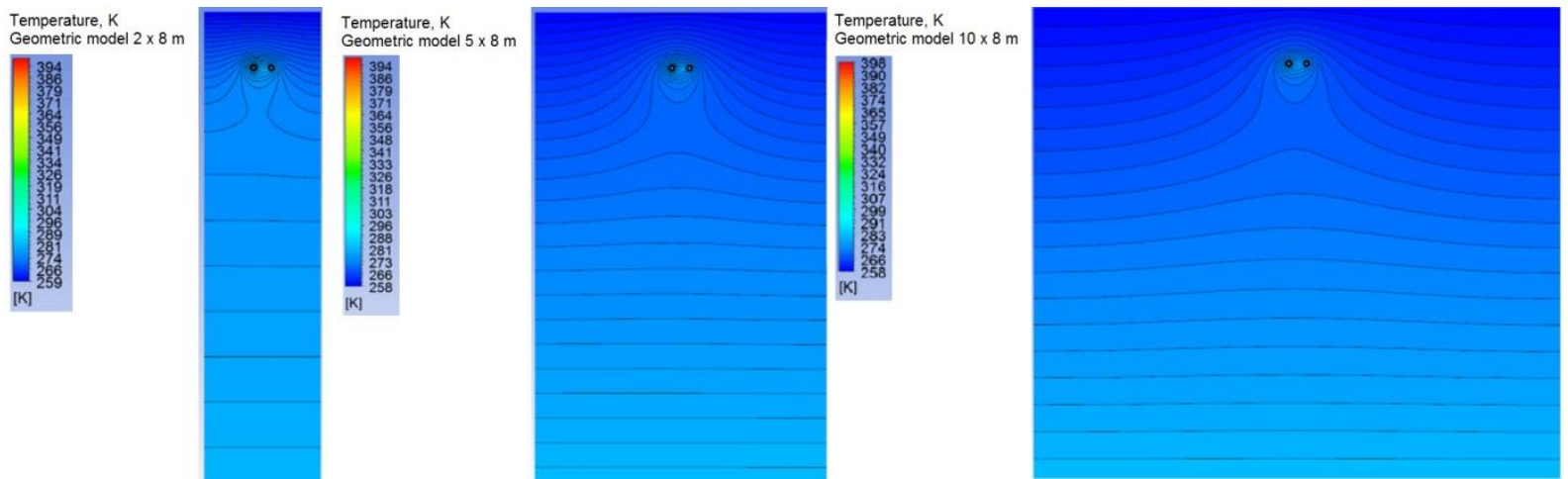

Figure 6: The ground temperature distribution for various variants of the geometric area width 


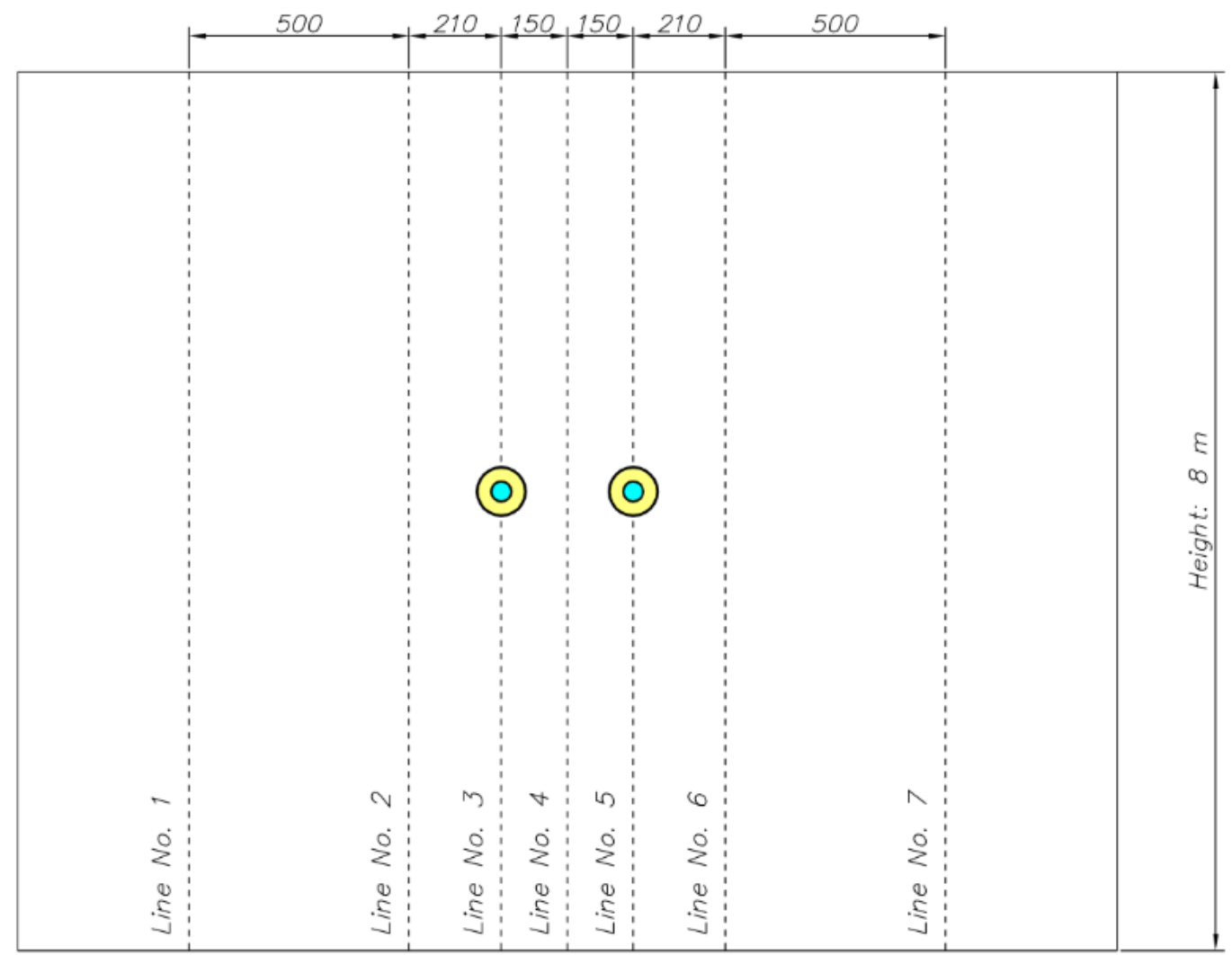

Figure 7: Scheme of the temperature profiles determination - lines 1-7

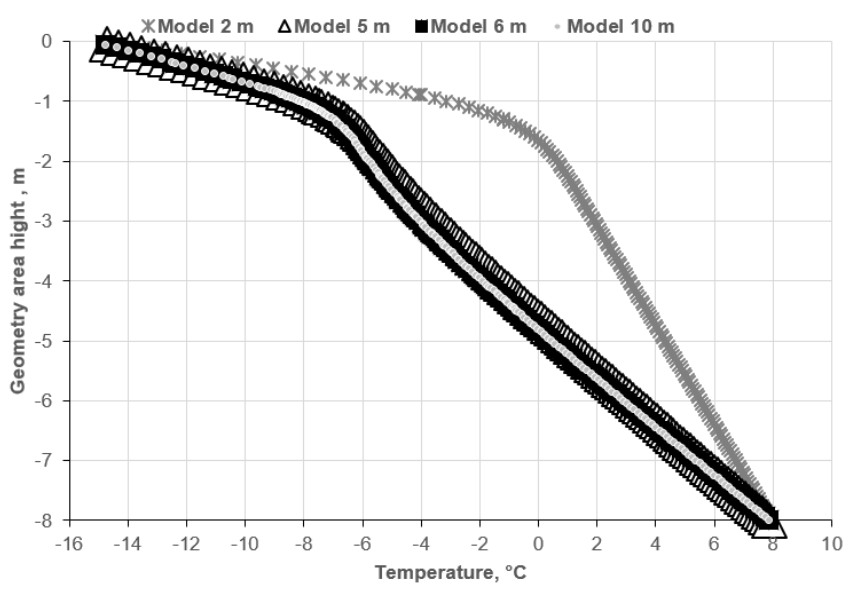

Figure 8: Temperature profiles along the line $n^{\circ} 1$ (model 2, 5, 6 and $10 \mathrm{~m}$ ) 


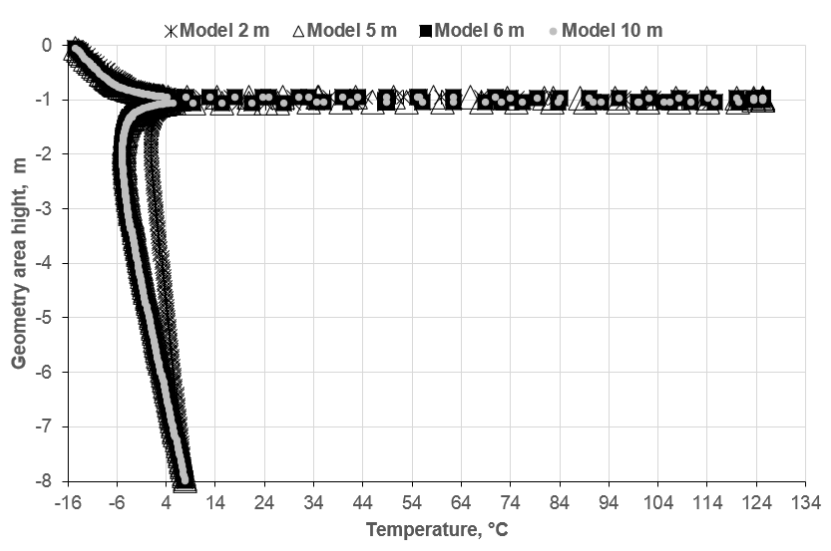

Figure 9: Temperature profiles along the $\operatorname{line} \mathrm{n}^{\circ} 3(\operatorname{model} 2,5,6$ and $10 \mathrm{~m})$

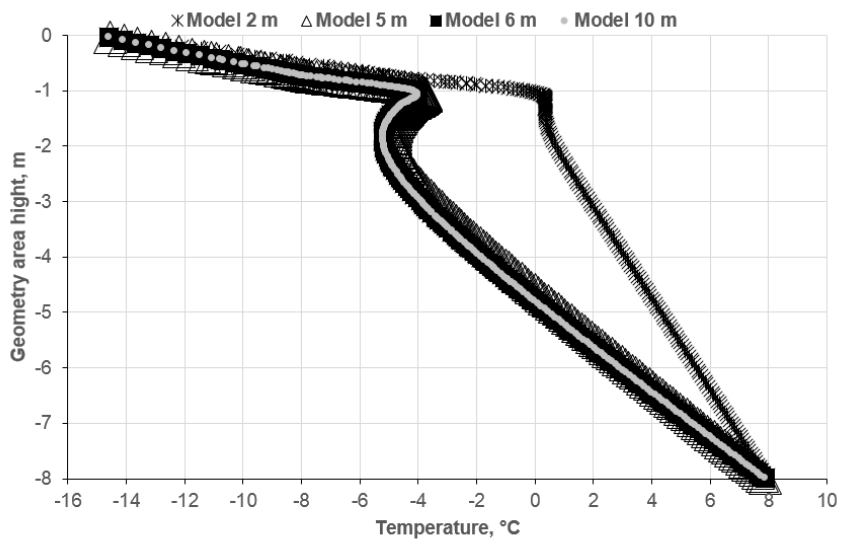

Figure 10: Temperature profiles along the line $n^{\circ} 6$ (model 2, 5, 6 and $10 \mathrm{~m}$ )

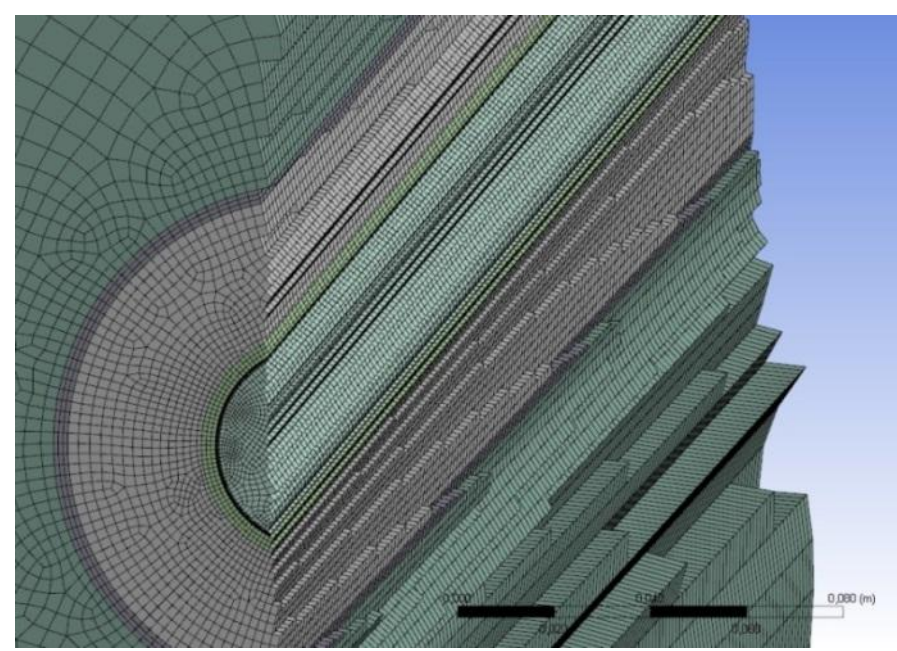

Figure 11: Hexahedral cells - the cross-section through the flow line of the pre-insulated pipe 


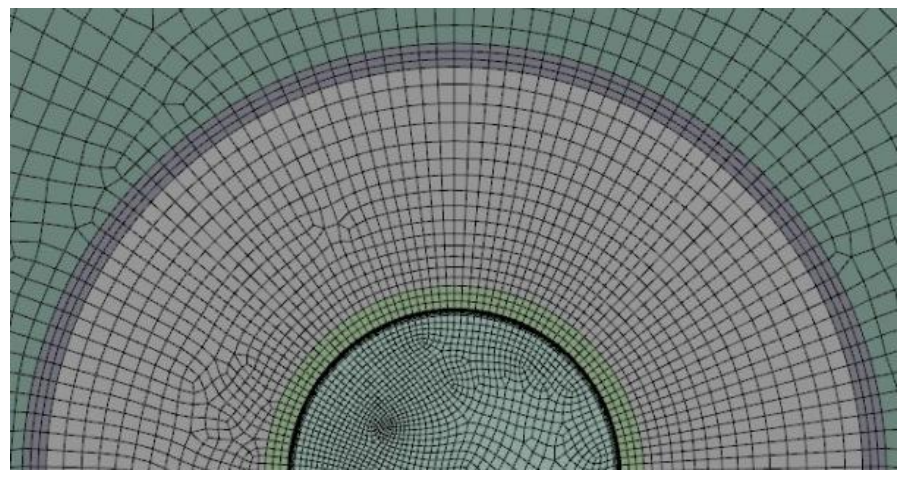

Figure 12: Section of numerical mesh after performing Mapped function
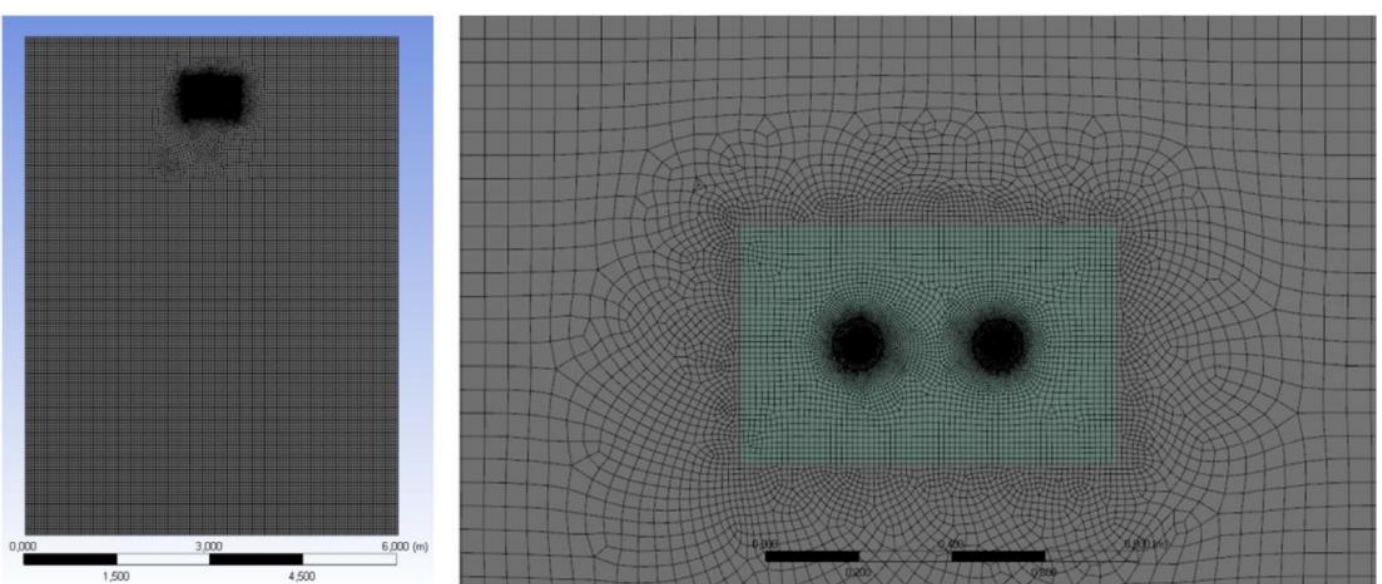

Figure 13: The areas of the mesh concentration in the computational model 


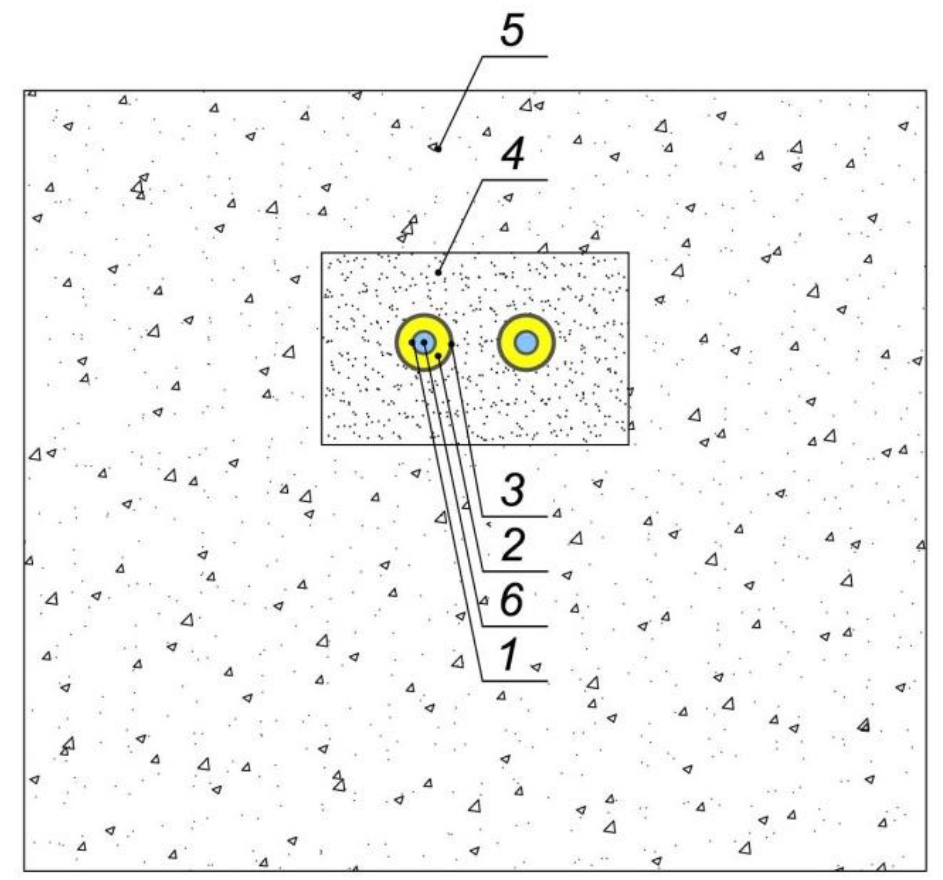

Figure 14: Computational domains in the numerical model

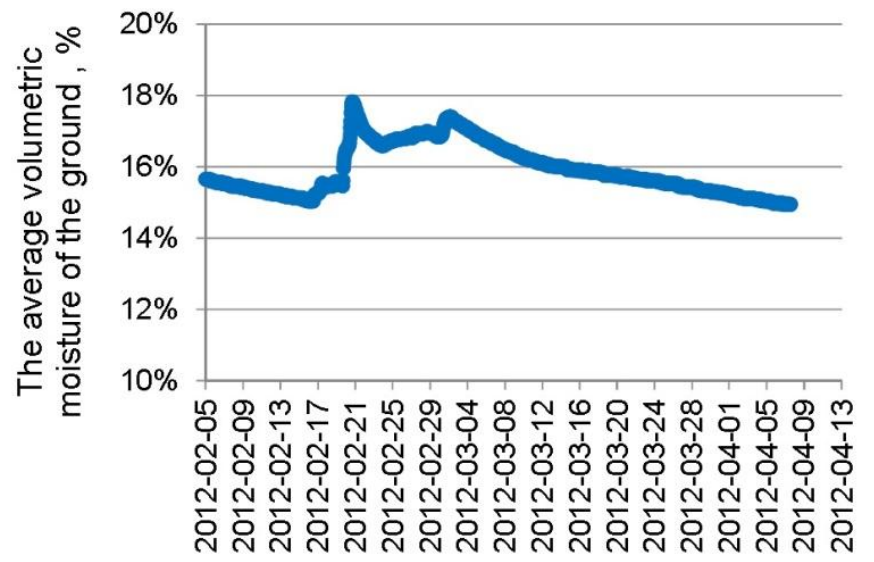

Time

Figure 15: The average volumetric moisture of the ground during the carried measurement (05.02.2012 - 07.04.2012) 


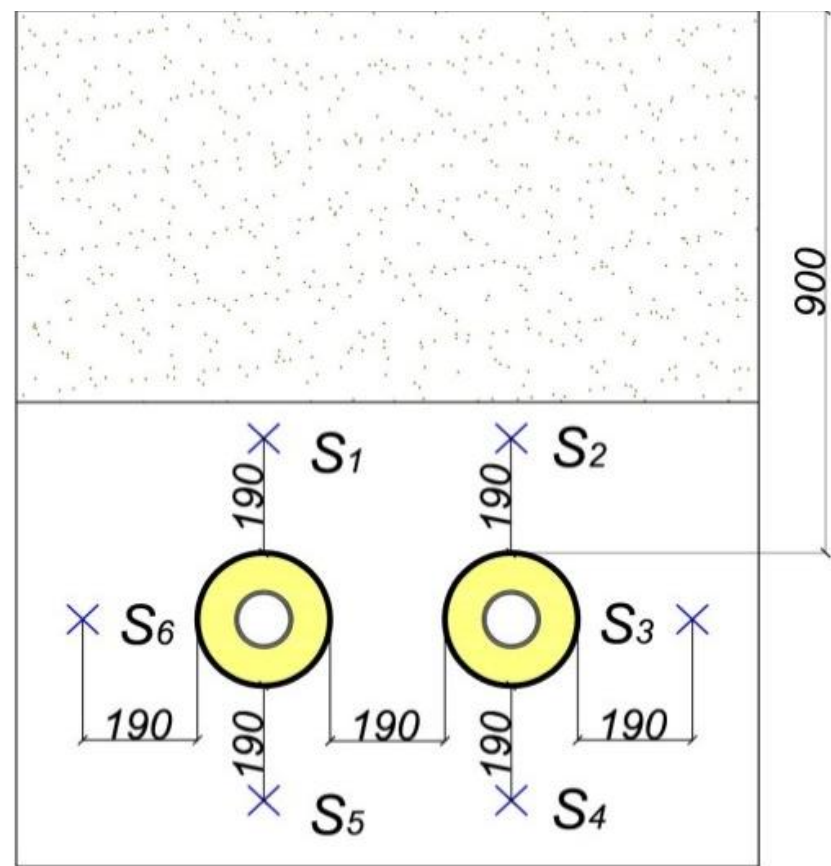

Figure 16: The ground volumetric moisture measuring probe location around the pipeline

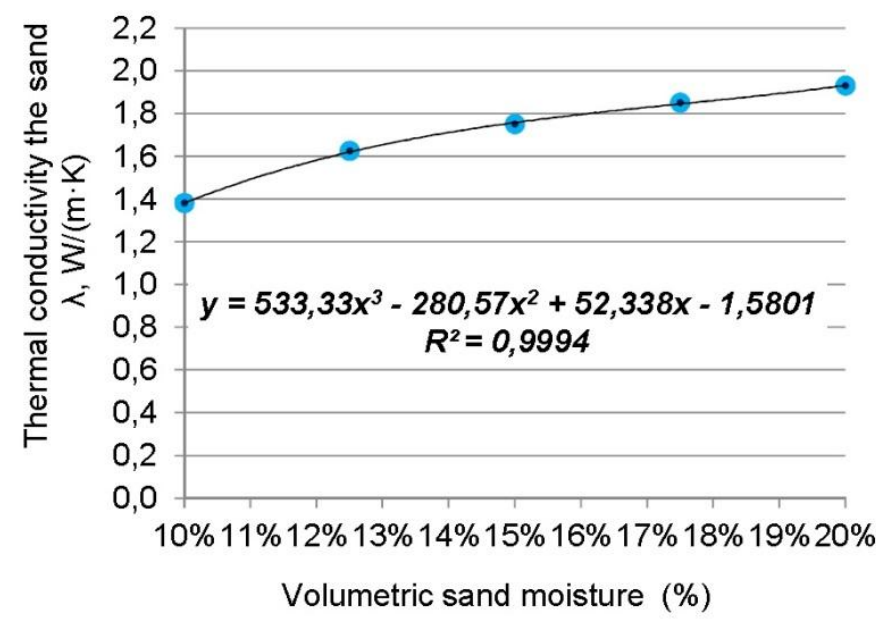

Figure 17: The ground thermal conductivity in function of the ground volumetric moisture around the pipelines

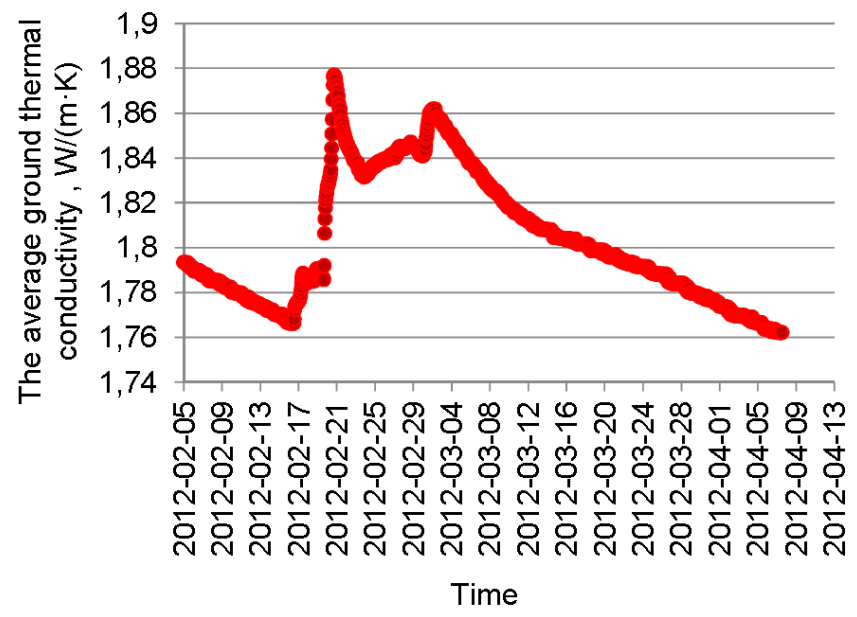

Figure 18: The ground thermal conductivity around the pre-insulated pipelines (05.02.2012 07.04.2012) 


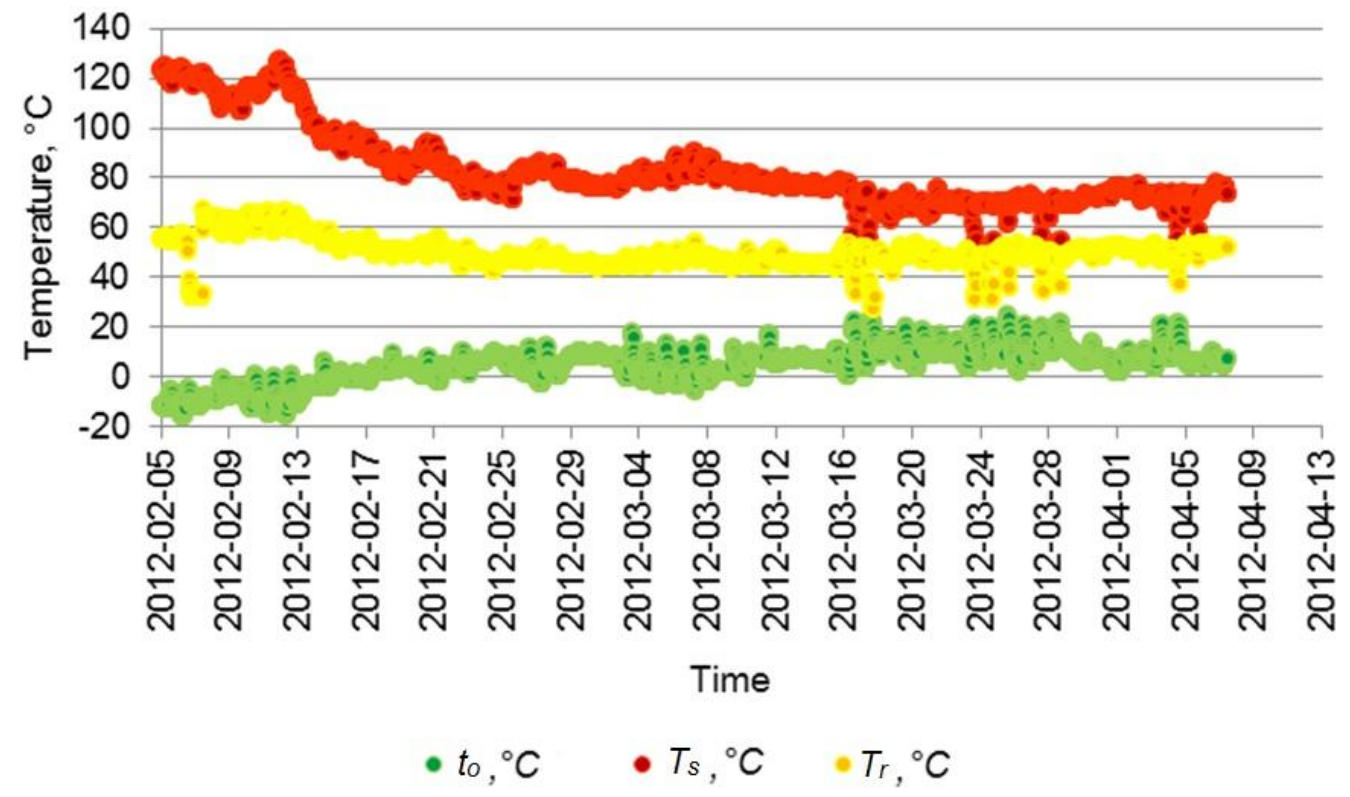

Figure 19: The circulating water and external air temperatures measured on the experimental stand (05.02.2012 - 07.04.2012)

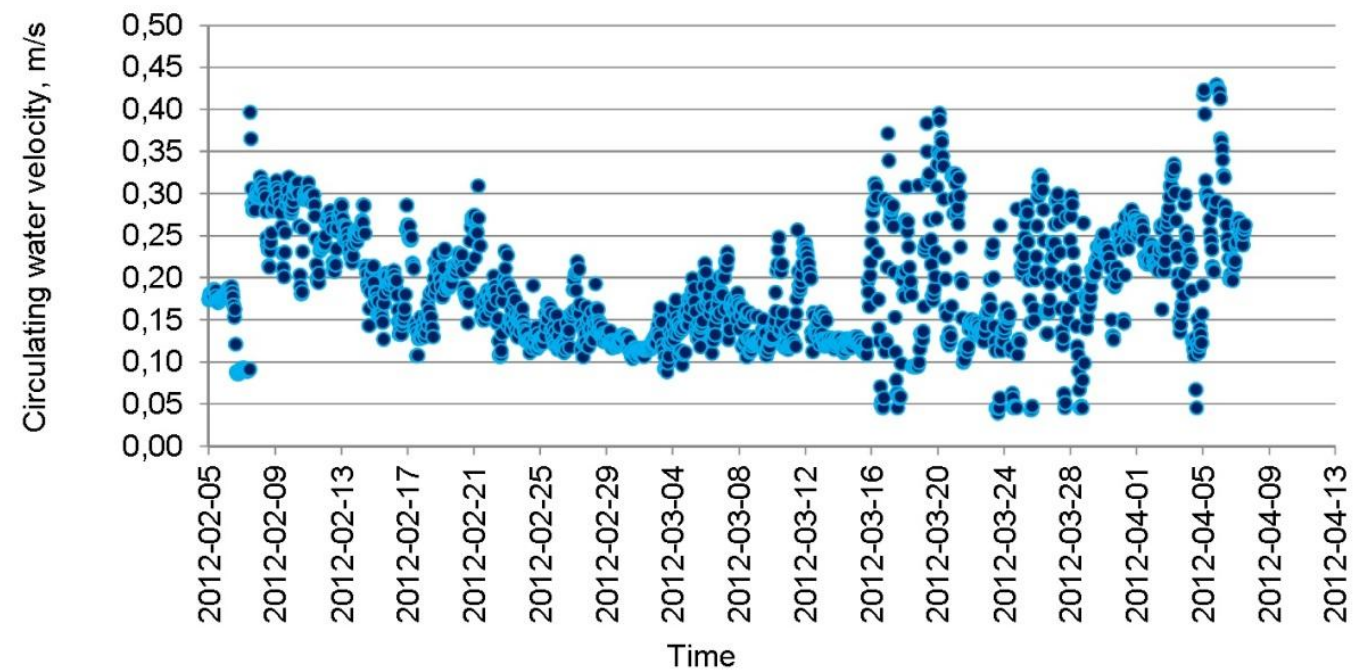

Figure 20: The circulating water velocity in the district heating connection (05.02.2012 07.04.2012) 


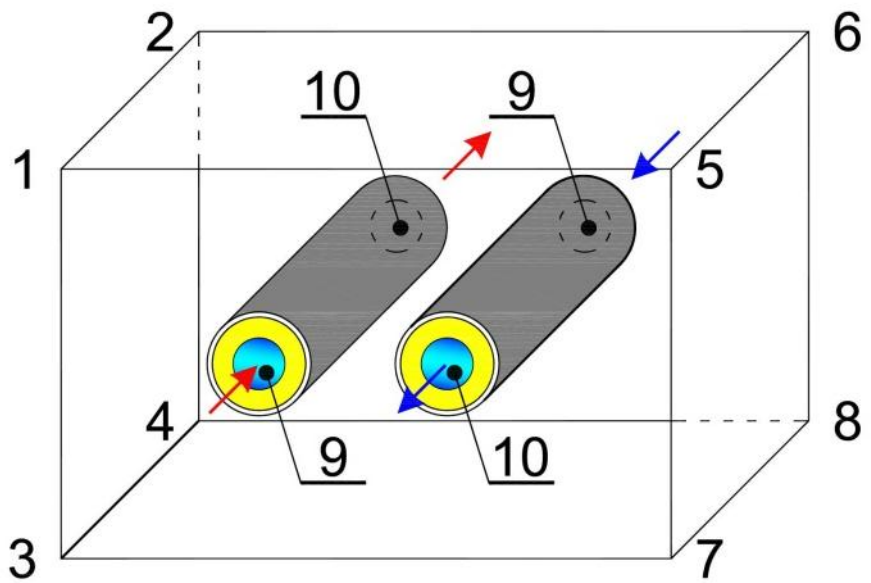

Figure 21: Scheme of the boundary conditions indication in the three dimensional computational model

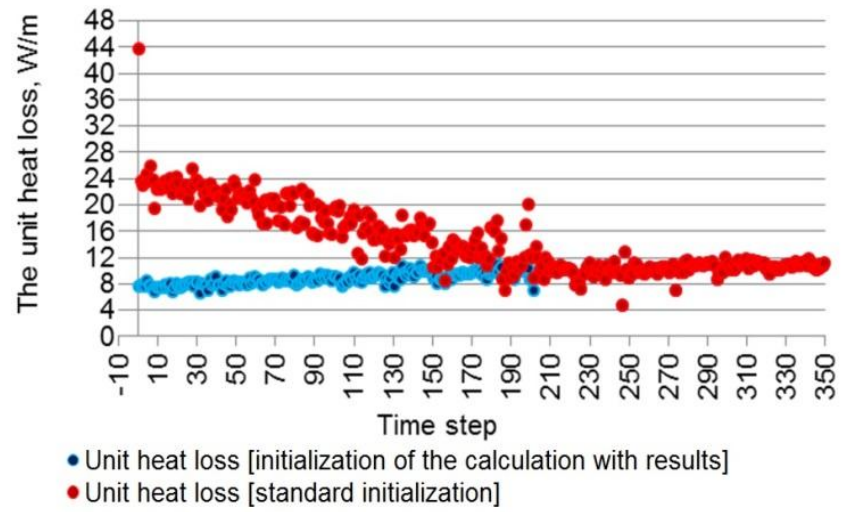

Figure 22: The outcomes of the unit heat loss computation obtained basing on numerical model in case of two different kinds of initial condition assumptions 


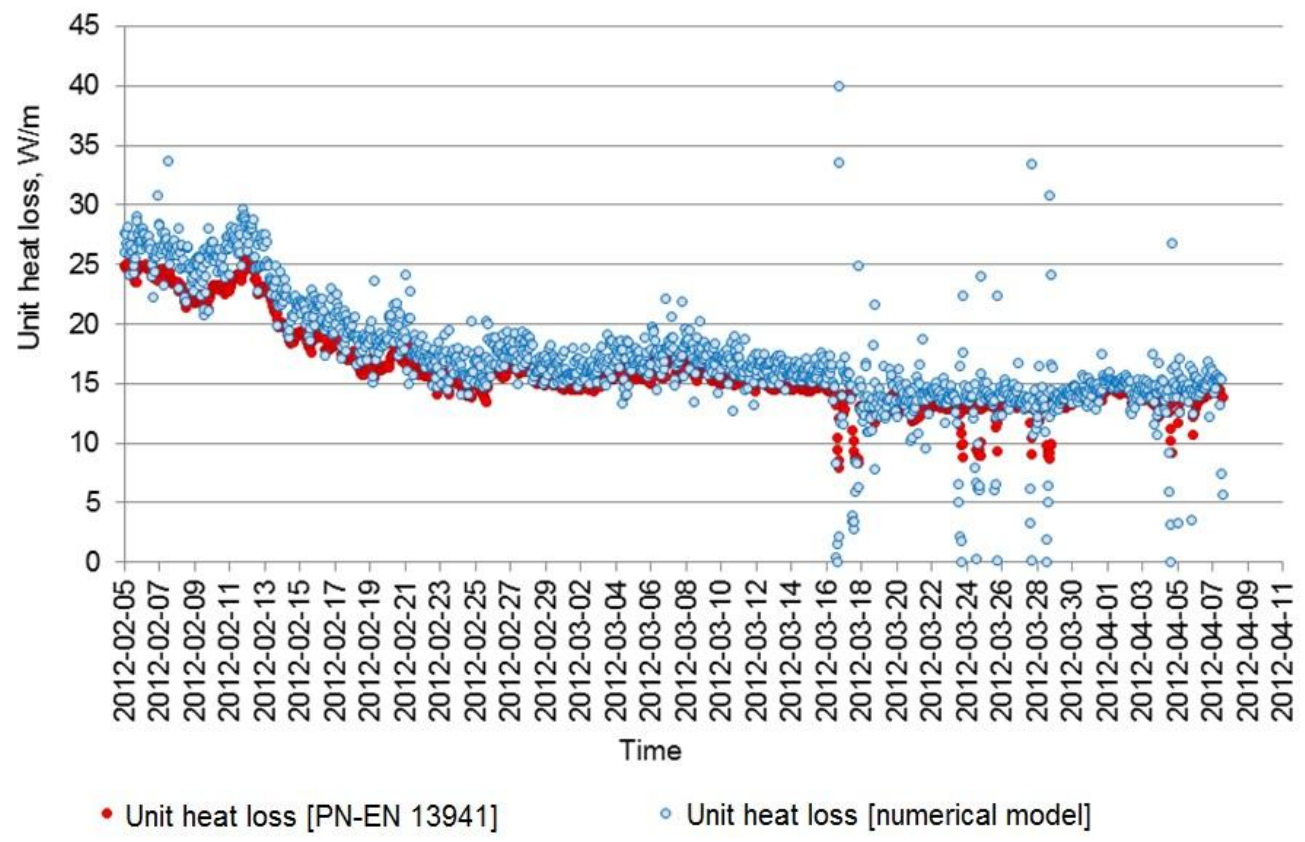

Figure 23: The outcomes of the unit heat loss calculation in the flow pipe based on the PN-EN standard guidelines and computation with the numerical model

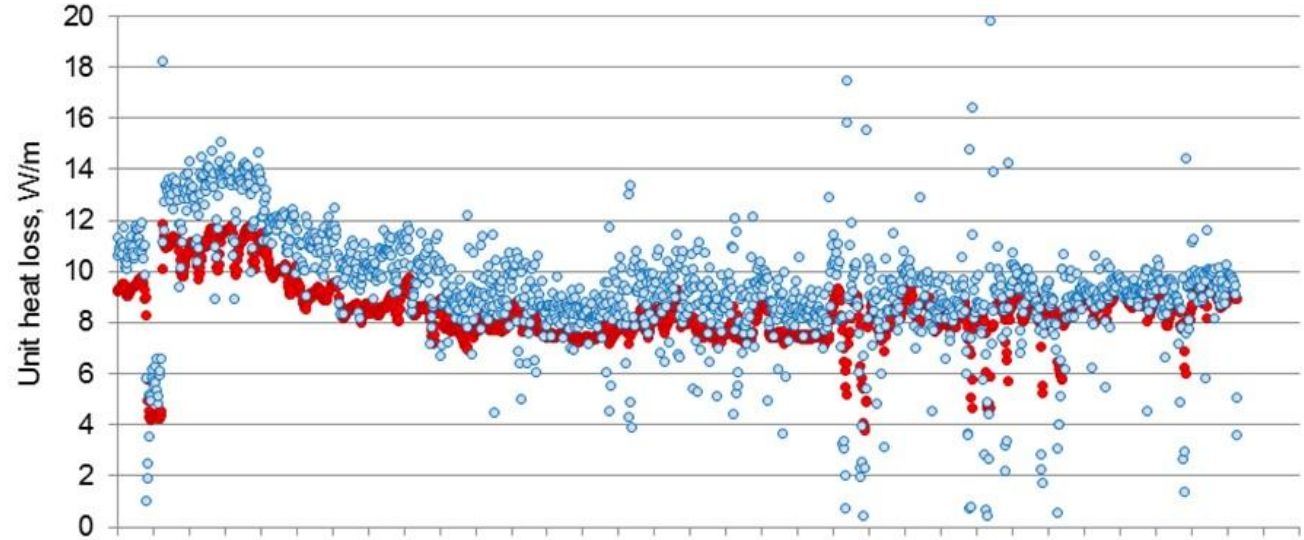

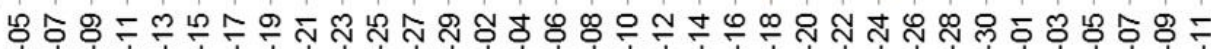

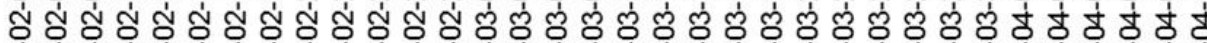
ง

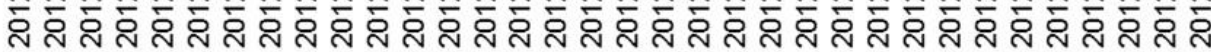
Time

- Unit heat loss [PN-EN 13941] $\quad \circ$ Unit heat loss [numerical model]

Figure 24: The outcomes of the unit heat loss calculation in the return pipe basing on the PN-EN standard guidelines and computation with the numerical model 


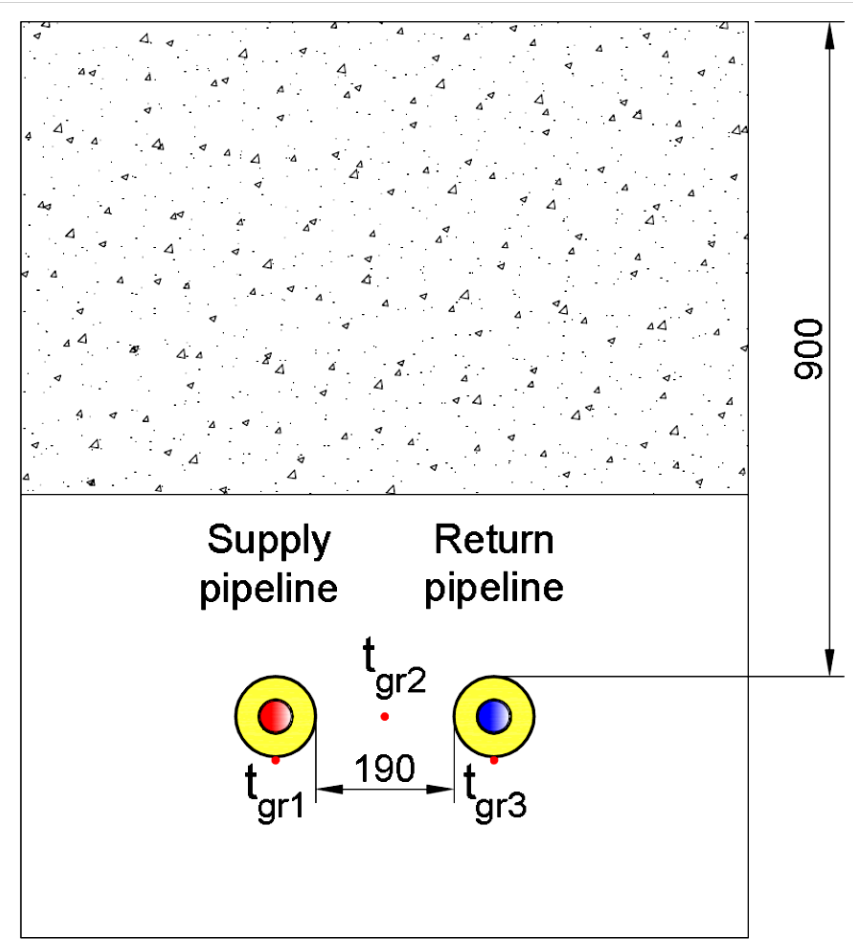

Figure 25: The locations of the ground temperature measurements (tgr1, tgr2, tgr3)

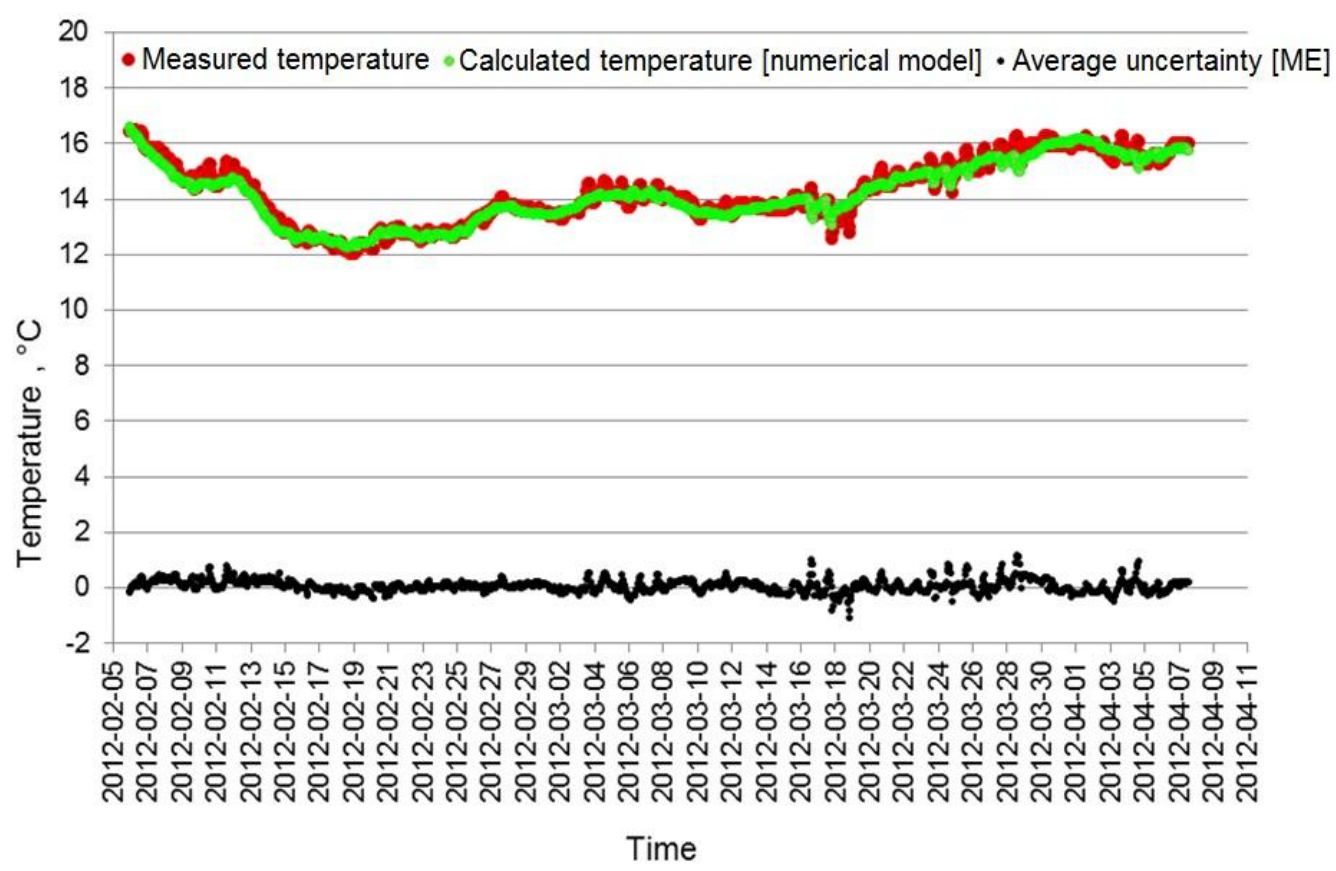

Figure 26: The outcomes of the measurements and calculation of the ground temperature in point $\left(t_{\mathrm{gr} 1}\right)$ 


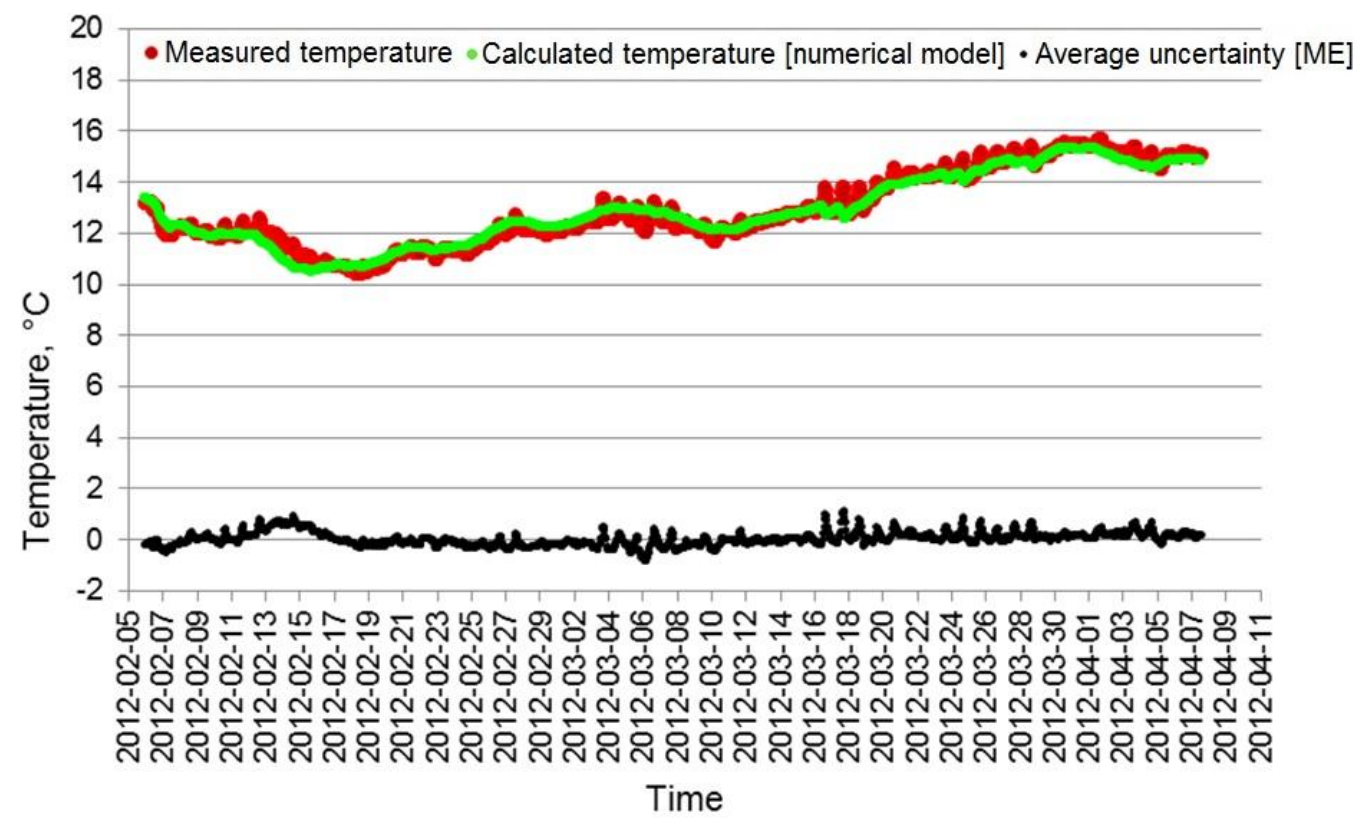

Figure 27: The outcomes of the measurements and calculation of the ground temperature in point $\left(t_{g r 2}\right)$

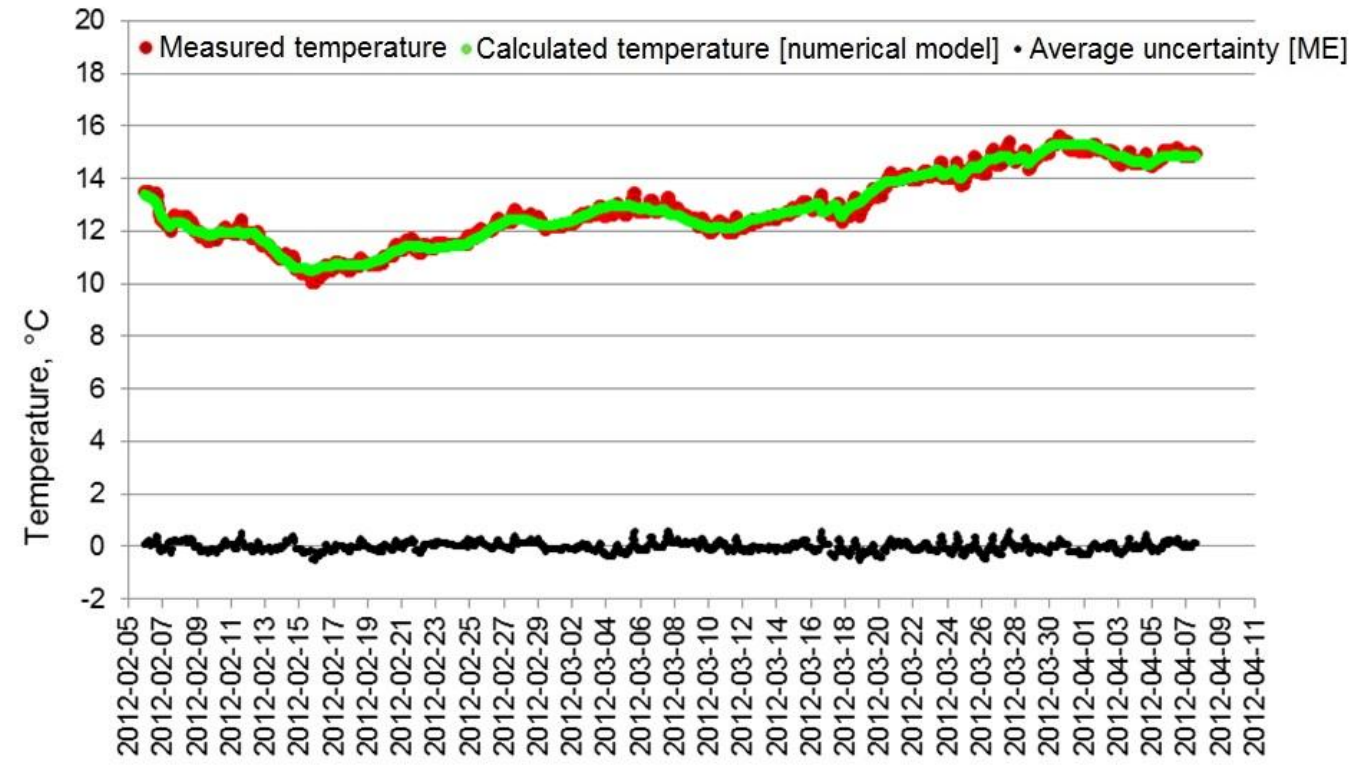

Time

Figure 28: The outcomes of the measurements and calculation of the ground temperature in point $\left(t_{\text {gr3 }}\right)$ 
Table 1 The dimensions of carrier and jacket pipes on the measurement site (dimensions are in mm)

\begin{tabular}{lllll}
\hline Nominal diameter & $\begin{array}{l}\text { External diameter of } \\
\text { outer jacket }\end{array}$ & $\begin{array}{l}\text { External diameter of } \\
\text { carrier pipe }\end{array}$ & $\begin{array}{l}\text { Internal diameter } \\
\text { of carrier pipe }\end{array}$ & Wall thickness \\
\hline$D N$ & $D_{0}$ & $D_{\text {out }}$ & $D_{\text {inn }}$ & $D_{w t}$ \\
40 & 110 & 48.3 & 43.1 & 2.6 \\
\hline
\end{tabular}

Table 2 Values of the mesh quality indicating parameters

\begin{tabular}{lllll}
$\begin{array}{l}\text { Mesh quality indicating } \\
\text { parameters }\end{array}$ & $\begin{array}{l}\text { Minimum value characteristic for } \\
\text { the single computational cell }\end{array}$ & $\begin{array}{l}\text { Maximum value characteristic for } \\
\text { the single computational cell }\end{array}$ & $\begin{array}{l}\text { Average } \\
\text { value }\end{array}$ & $\begin{array}{l}\text { Acceptable } \\
\text { range }\end{array}$ \\
\hline Orthogonal Quality & 0.52 & 1 & 0.99 & $0.33-1$ \\
Skewness & $1.3 \times 10^{-10}$ & 0.72 & 0.05 & $0-0.75$ \\
\hline
\end{tabular}

Table 3 Thermophysical properties of the computational domains in the numerical model

\begin{tabular}{lllll}
\hline Name & Material & $\lambda, \mathrm{W} /(\mathrm{m} \cdot \mathrm{K})$ & $\mathrm{C}, \mathrm{J} /(\mathrm{kg} \cdot \mathrm{K})$ & $\rho, \mathrm{kg} / \mathrm{m}^{3}$ \\
\hline Carrier pipe & Steel & 60 & 452 & 7860 \\
Insulation & PUR foam & 0.029 & 1200 & 80 \\
Outer jacket & PE - HD & 0.4 & 1900 & 965 \\
Covering layers & Sand & The “Variable_lambda” algorithm & 1185 & 1800 \\
Ground & Ground & 1.6 & 1050 & 1760 \\
Water & According to the database of the ANSYS® 14.5 application & \\
\hline
\end{tabular}

